\title{
Article \\ Screening for the Active Anti-Inflammatory and Antioxidant Polyphenols of Gaultheria procumbens and Their Application for Standardisation: From Identification through Cellular Studies to Quantitative Determination
}

\author{
Monika Anna Olszewska ${ }^{1}(\mathbb{D})$, Aleksandra Owczarek ${ }^{1}\left(\mathbb{D}\right.$, Anna Magiera $^{1}$ (D), Sebastian Granica ${ }^{2}(\mathbb{D}$ \\ and Piotr Michel ${ }^{1, *(D)}$
}

1 Department of Pharmacognosy, Faculty of Pharmacy, Medical University of Lodz, Muszynskiego 1 St., 90-151 Lodz, Poland; monika.olszewska@umed.lodz.pl (M.A.O.); aleksandra.owczarek@umed.lodz.pl (A.O.); anna.magiera@umed.lodz.pl (A.M.)

2 Microbiota Lab, Centre for Preclinical Studies, Department of Pharmacognosy and Molecular Basis of Phytotherapy, Medical University of Warsaw, 1 Banacha St., 02-097 Warsaw, Poland; sgranica@wum.edu.pl

* Correspondence: piotr.michel@umed.lodz.pl; Tel.: +48-426779169

Citation: Olszewska, M.A.;

Owczarek, A.; Magiera, A.; Granica, S.; Michel, P. Screening for the Active Anti-Inflammatory and Antioxidant Polyphenols of Gaultheria procumbens and Their Application for

Standardisation: From Identification through Cellular Studies to Quantitative Determination. Int. J. Mol. Sci. 2021, 22, 11532. https:// doi.org/10.3390/ijms222111532

Academic Editor: Davide Barreca

Received: 20 September 2021

Accepted: 21 October 2021

Published: 26 October 2021

Publisher's Note: MDPI stays neutral with regard to jurisdictional claims in published maps and institutional affiliations.

Copyright: (c) 2021 by the authors Licensee MDPI, Basel, Switzerland. This article is an open access article distributed under the terms and conditions of the Creative Commons Attribution (CC BY) license (https:// creativecommons.org/licenses/by/ $4.0 /)$.

\begin{abstract}
Aerial parts, leaves, and stems of Gaultheria procumbens are polyphenol-rich herbal medicines with anti-inflammatory and antioxidant effects. The present study focused on identifying active markers of the G. procumbens extracts in an integrated approach combining phytochemical and biological capacity tests. The target compounds, representing all classes of Gaultheria polyphenols, were pre-selected by LC-ESI-PDA-MS/MS. For unambiguous identification, the key analytes, including a rare procyanidin trimer (cinnamtannin B-1), miquelianin potassium salt, and two new natural products: quercetin and kaempferol 3-O- $\beta$-D-xylopyranosyl- $(1 \rightarrow 2)-\beta$-D-glucuronopyranosides, were isolated by preparative HPLC and investigated by spectroscopy (HR-ESI-MS, UV-vis, CD, 1D- and 2D-NMR), thiolysis, flame photometry, optical rotation experiments, and absolute configuration studies. The significant contribution of the pre-selected compounds to the biological effects of the extracts was confirmed in vitro: the analytes significantly and in a dose-dependent manner downregulated the pro-oxidant and pro-inflammatory functions of human neutrophils ex vivo (inhibited the release of reactive oxygen species, IL- $1 \beta$, TNF- $\alpha$, and neutrophils elastase, ELA-2), inhibited two key pro-inflammatory enzymes (cyclooxygenase, COX-2, and hyaluronidase), and most of them, except gaultherin, exerted potent direct antioxidant activity (ferric reducing antioxidant power and superoxide anion scavenging capacity). Moreover, cellular safety was confirmed for all compounds by flow cytometry. Eventually, as these mechanisms have been connected to the health benefits of G. procumbens, 11 polyphenols were accepted as active markers, and a simple, accurate, reproducible, and fully validated RP-HPLC-PDA method for standardisation of the target extracts was proposed.
\end{abstract}

Keywords: Gaultheria procumbens; anti-inflammatory activity; antioxidant activity; isolation; structure elucidation; quercetin 3-O- $\beta$-D-xylopyranosyl- $(1 \rightarrow 2)-\beta$-D-glucuronopyranoside; miquelianin potassium salt; gaultherin; cinnamtannin B-1; standardisation

\section{Introduction}

Quality control (QC) is the main factor in guaranteeing the therapeutic effectiveness and safety of herbal medicines [1]. However, plant-based products are usually complex mixtures with no apparent targets for standardisation [2]. The most profitable strategy for selecting QC markers is based on the biological potency of the individual compounds and their contribution to the pharmacological effects of herbal products [3]. On the other hand, two sets of analytical procedures are recommended for the QC process: chromatographic fingerprinting with mass spectral (MS) detection (for authentication purposes) 
and specific quantitative assays of selected phytochemicals that drive therapeutic properties $[4,5]$. Considering the molecular diversity of plant constituents, proper structural annotation of fingerprints is still challenging despite the advantages of multistage mass spectral $\left(\mathrm{MS}^{n}\right)$ profiling [6]. In the case of rare phytochemicals, especially glycosides, identification of their detailed structural features, such as the absolute configuration of sugar components, glycosylation position of polyhydroxylated aglycones or interglycosidic linkage in polyglycosides, requires their isolation from the plant material and the application of some additional analytical techniques including nuclear magnetic resonance (NMR) spectroscopy. With the low availability of authentic standards of rare compounds, isolation is also the most reliable way to confirm their pharmacological effects $[3,6]$. Consequently, combined phytochemical and biological activity studies are necessary to identify and select active markers among numerous candidate constituents of the target plant.

An example of a medicinal plant lacking standardisation procedures is Gaultheria procumbens L. (American wintergreen, Ericaceae). This evergreen shrub occurs naturally in northeastern North America and is cultivated worldwide in the temperate zone for ornamental and therapeutic purposes. Leaves, stems, and whole aerial parts of G. procumbens are anti-inflammatory, analgesic, and antioxidant agents recommended for treating rheumatoid arthritis, influenza, cold, fever, tracheitis, pharyngitis, pain of various aetiology, and some skin and periodontal diseases [7,8]. The genus Gaultheria is known for salicylate glycosides, a rare class of natural analogues of aspirin [7-9]. The leading compound, gaultherin (GT), exerts potent anti-inflammatory activity by modulation of pro-inflammatory functions of immune cells, especially secretion of pro-inflammatory cytokines IL-1 $\beta$, IL-6, and TNF- $\alpha[10,11]$. GT is also known as a cyclooxygenase (COX-2) inhibitor [11], with a potency comparable to synthetic drugs [12]. However, apart from GT, G. procumbens accumulates various other polyphenols, which might be co-responsible for the therapeutic effects of the plant. In our previous LC-MS 3 studies, the leaves and stems of the plant revealed complex matrices with about 50 native polyphenols representing the groups of free catechins, mono- to trimeric procyanidins, flavonol glycosides, and quinic acid pseudodepsides $[11,13]$. Although there is a solid background of the anti-inflammatory and antioxidant activity of these compounds classes [14-16], no data are accessible on the contribution of individual non-salicylate constituents to the pharmacological effects of G. procumbens, which is required for the selection of active markers. There is also an information gap on the molecular structures of the Gaultheria components. According to our earlier surveys [11,13], at least two primary components of the leaves and stems of G. procumbens, a flavonoid diglycoside and a procyanidin A-type trimer, cannot be structurally identified without isolation from the plant. Moreover, in the course of fractionated extraction of the leaves [13], we observed the decreased solubility of the extracts with the increasing presence of the compound identified by LC-MS ${ }^{3}$ with the standard of quercetin 3-glucuronide (miquelianin, MQ), which suggests that the corresponding native constituent might have modified structure. Apart from the structural issues, no fully validated method exists for the quantitative determination of the G. procumbens phytochemicals. The first attempt to optimise the appropriate procedure was performed by Saleem et al. [17], who developed an HPLC-PDA-APCI/MSD method to analyse selected polyphenols in various Ericaceae plants, including G. procumbens. However, the obtained results are unsatisfactory in terms of peak resolution and peak annotation (some critical peaks co-eluted or were unidentified) and the range of validation tests (only limits of detection and limits of quantitation presented).

Therefore, the present work aimed to select active markers of G. procumbens and to develop and fully validate an HPLC-PDA method suitable for QC of the leaf, stem, and aerial parts extracts of the plant. The task was accomplished by applying various chromatographic (analytical and preparative) and spectroscopic techniques and biological capacity tests in an integrated approach. In the first step, 11 model polyphenols were pre-selected based on a UHPLC-PDA-ESI-MS ${ }^{3}$ analysis of the extracts. For complete structural identification, seven of the critical analytes and four minor components were 
isolated from the plant material by a combination of gel permeation chromatography (GPC), flash chromatography, and preparative HPLC, and analysed by spectroscopic (HRESI-MS, ${ }^{1} \mathrm{H}$ NMR, ${ }^{13} \mathrm{C}$ NMR, COSY, HMQC, HMBC, and ROESY), hydrolytic, thiolytic, and absolute configuration studies. In some cases, additional CD, optical rotation, and flame photometric experiments were performed. Based on the known bioactivity mechanism of Gaultheria plants [10-13,18-21], the selected compounds were tested in non-cellular and cellular in vitro models for antioxidant and anti-inflammatory activity, including ferric reducing antioxidant power (FRAP), scavenging of superoxide anion $\left(\mathrm{O}_{2}{ }^{\bullet-}\right)$, inhibition of pro-inflammatory enzymes (COX-2, and hyaluronidase, HYAL), and modulation of pro-oxidant and pro-inflammatory functions of human neutrophils ex vivo (release of ROS, IL-1 $\beta$, TNF- $\alpha$ and elastase, ELA-2). The influence of the analytes on the viability of neutrophils was also evaluated. Eventually, the selected analytes were proposed as standardisation markers, and an HPLC-PDA method was developed and validated for quantitative profiling of the extracts.

\section{Results and Discussion}

\subsection{Selection of Model Compounds and Structural Studies}

Among different plant parts of G. procumbens, the leaves and aerial parts (whole twigs with leaves) are the most frequently used for medicinal purposes $[7,8]$. In the present study, the aerial parts were used for QC method development because they combine the chemical matrices of leaves and stems (twigs). The plant material was extracted with methanol-water $(75: 25, v / v)$, the solvent optimised for the recovery of polyphenols from leaves and stems $[11,13]$. The phytochemical profile of the extract (ME-AP) was studied by UHPLC-PDA-ESI-MS ${ }^{3}$, and the analytes (UHPLC peaks 1-41, Figure 1) were initially identified (Table S1) by comparing their retention times, UV-vis spectra, and MS/MS fragmentation profiles with the standards and literature data [22-24]. Considering the previously characterised profiles of leaves and stems [11,13], 11 compounds (coloured peaks in Figure 1) were selected as model structures for G. procumbens polyphenols.

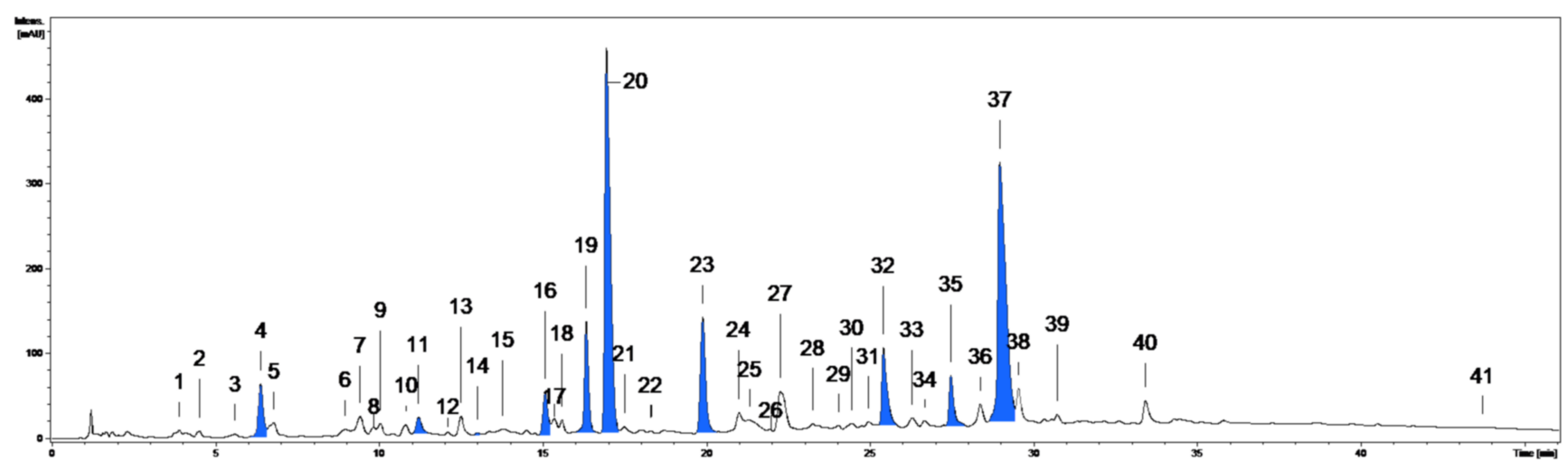

Figure 1. Representative UHPLC-PDA chromatogram of the aerial parts extract ME-AP at $280 \mathrm{~nm}$. The peak numbers refer to those implemented in Table S1. The model compounds (coloured peaks): 4, NCHA (neochlorogenic acid); 11, CHA (chlorogenic acid); 14, CCHA (cryptochlorogenic acid); 16, PB2 (procyanidin B2); 19, ECA ((-)-epicatechin); 20, GT (gaultherin); 23, CB1 (cinnamtannin B-1); 32, DGQ (wintergreenoside A); 35, HY (hyperoside); 37, MQ (miquelianin); 41, QU (quercetin).

They were assigned as GT, a representative of methyl salicylate glycosides; (-)epicatechin (ECA) from the group of monomeric flavanols; procyanidin B2 (PB2) and a procyanidin A-type trimer (CB1) as oligomeric proanthocyanidins; chlorogenic acid (CHA), neochlorogenic acid (NCHA), and cryptochlorogenic acid (CCHA), three isomeric caffeoylquinic acids, and MQ, hyperoside (HY), and a quercetin pentoside-glucuronide (DGQ), representing the flavonoid glycosides. Moreover, a flavonoid aglycone quercetin (QU) was added to the set as a useful marker of hydrolytic degradation of the extracts during processing. 
Two of the selected compounds, CB1 and DGQ, had to be isolated for complete structural identification. For isolation purposes, the defatted extract (MED-AP) of aerial parts was obtained on a preparative scale and fractionated by liquid-liquid partitioning for basic clean-up [13]. The ballast substances, extracted with chloroform and diethyl ether, were discarded, and the target analytes were concentrated in the fractions of ethyl acetate (EAF-AP), $n$-butanol (BF-AP), and water (WF-AP). Apart from CB1 and DGQ, also some relatively hydrophilic polyphenols, including flavonoid monoglycosides, were present in EAF-AP and BF-AP. However, despite similarities in LC-MS/MS profiles, the solubility of EAF-AP and BF-AP in methanol differed significantly. BF-AP was surprisingly hardly soluble and tended to precipitate some yellowish pigment. To explain this phenomenon, EAF-AP and BF-AP were subjected to GPC to separate the fractions of flavonoids and procyanidins and the sparingly soluble component (MQK) of BF-AP was obtained from the respective flavonoid fraction by crystallisation. Eventually, WF-AP and the procyanidin and flavonoid fractions of EAF-AP were chromatographed using GPC, flash chromatography, and preparative HPLC to yield the target compounds (CB1 and DGQ) and several accompanying constituents (GT, ECA, PB2, MQ, HY, IQ, GV, KG, DGK).

CB1 (Figure 2) showed a UV absorption maximum at $278 \mathrm{~nm}$ and a $[\mathrm{M}-\mathrm{H}]^{-}$ion at $863 \mathrm{~m} / z$ (LC-PDA-ESI-MS ${ }^{3}$ ), suggesting that it is an A/B-type proanthocyanidin trimer with one A-type interflavan bond and the molecular formula of $\mathrm{C}_{45} \mathrm{H}_{36} \mathrm{O}_{18}$ [23]. The secondary ions (negative ions mode) at $m / z 711,573,559,407,289$, and 285 indicated that the trimer is composed of three (epi)catechin units and its fragmentation scheme (Figure S1) was typical of both A- and B-type procyanidins [23,25]. The trimeric structure was confirmed by $45^{13} \mathrm{C}$ NMR signals (Table S2), including 3 sets of aliphatic carbon signals typical of C-2 (79.9-101.2 ppm), C-3 (68.2-73.6 ppm), and C-4 (29.9-39.3 ppm) positions in the pyran rings [26]. The presence of one A-type interflavan linkage was confirmed by the downfield shift of one of the C-2 signals (101.2 ppm, typical of ketal carbons) in comparison to the other two resonances (79.9 and $81.4 \mathrm{ppm})[26,27]$. Moreover, the ${ }^{1} \mathrm{H}$ NMR spectrum exhibited the presence of 22 proton resonances (Table S3) against 23 signals required for B-type procyanidins $[23,26]$. The complete signal assignments of the protons and carbon atoms were achieved using 2D NMR experiments (COSY, HMQC, HMBC). Accordingly, the A-type linkage was confirmed by the presence of two proton doublets at $\delta_{\mathrm{H}} 3.34 \mathrm{ppm}(1 \mathrm{H}, d, J=3.4 \mathrm{~Hz})$ and $4.19 \mathrm{ppm}(1 \mathrm{H}, d, J=3.4 \mathrm{~Hz})$ corresponding to $\mathrm{H}-3$ and $\mathrm{H}-4$ in the ring $\mathrm{C}$ and the lack of $\mathrm{H}-2$. The configuration of the interflavan bonds at $C-4(C)$ and $C-4(F)$ was established as $\beta$ according to the positive Cotton effect in the short wavelength region $\left([\Theta]_{228}+2.3 \times 10^{4}\right)$ of the $C D$ spectrum, while the negative effect at $270-290 \mathrm{~nm}\left([\Theta]_{270}-2.5 \times 10^{4}\right)$ suggested the $\alpha$ orientation of the phenyl rings (B, E, H) $[28,29]$. One pair of doublets with a small vicinal coupling constant $(J=3.4 \mathrm{~Hz})$ corresponding to trans relative substitution of $\mathrm{H}-3(\mathrm{C})$ and $\mathrm{H}-4(\mathrm{C})$, as well as four broad singlets of $\mathrm{H}-2(\mathrm{~F} / \mathrm{I})$ and $\mathrm{H}-3(\mathrm{~F} / \mathrm{I})$, according to cis relative substitutions at $\mathrm{C}-2(\mathrm{C} / \mathrm{F} / \mathrm{I})$ and $\mathrm{C}-3(\mathrm{C} / \mathrm{F} / \mathrm{I})$, suggested that $\mathrm{CB} 1$ is composed of three (-)-epicatechin subunits [30,31]. The structure of the terminal unit was additionally supported by thiolysis of CB1 and detection of (-)-epicatechin by HPLC-PDA after separation on a chiral column. The specific positions of the B-type linkages between the subunits were established using a combination of 2D NMR through-bond and through-space correlations. The HMBC cross-peaks between the proton $\mathrm{H}-4(\mathrm{C})$ and the carbon atoms $\mathrm{C}-8(\mathrm{D})$ and $\mathrm{C}-7(\mathrm{D})$ indicated the interflavan bond location between the upper and middle subunits. It was further confirmed by the low-temperature ROESY experiment and the correlations between $\mathrm{H}-2^{\prime}$ and $\mathrm{H}-6^{\prime}$ of the ring $\mathrm{E}$ and $\mathrm{H}-4$ of the ring $\mathrm{C}$, resulting from their spatial proximity and being characteristic of $4 \rightarrow 8$ linkages [30]. The $4 \rightarrow 8$ interflavan bond between the middle and the terminal (-)-epicatechin units was established analogously. Eventually, CB1 was identified as (-)-epicatechin- $(4 \beta \rightarrow 8,2 \beta \rightarrow O \rightarrow 7)-(-)$-epicatechin- $(4 \beta \rightarrow 8)-(-)$-epicatechin (cinnamtannin B-1). CB1 is a rare procyanidin that was for the first time isolated from the bark of Cinnamomum zeylanicum and is known for its potent antioxidant activity with neuro- and cardioprotective effects [32]. 


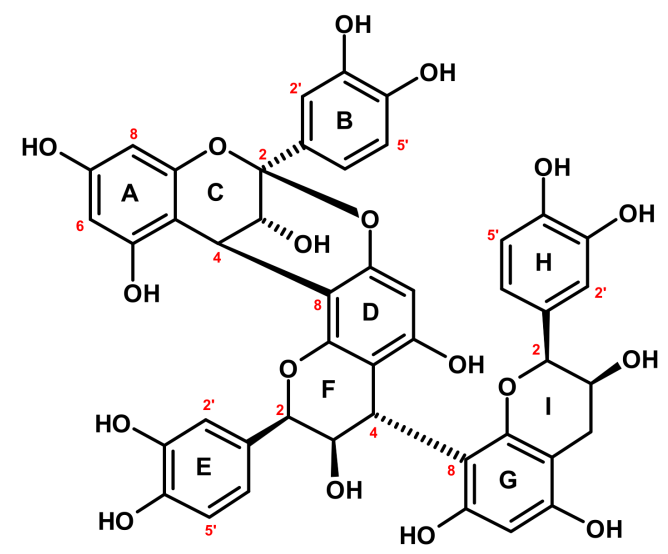

Figure 2. Structure of the isolated procyanidin trimer CB1 (cinnamtannin B-1). Atom numbering in red.

DGQ (Figure 3) exhibited a UV-vis spectrum with two absorption maxima at $266 \mathrm{~nm}$ and $356 \mathrm{~nm}$, diagnostic for flavonol glycosides. The HR-ESI-MS spectrum revealed a $[\mathrm{M}-\mathrm{H}]^{-}$ion at $609.1078 \mathrm{~m} / \mathrm{z}$, which agrees with the mass $(609.1092)$ calculated for the molecular formula $\mathrm{C}_{26} \mathrm{H}_{26} \mathrm{O}_{17}$. The product ions at $m / z 477[\mathrm{M}-132-\mathrm{H}]^{-}, 433[\mathrm{M}-$ $176-\mathrm{H}]^{-}$, and $301[\mathrm{M}-132-176-\mathrm{H}]^{-}$in LC-PDA-ESI-MS ${ }^{3}$ assay indicated that DGQ is a quercetin pentoside hexuronide. The acid hydrolysis of the glycoside provided an aglycone, identified by HPLC-PDA as quercetin [33], and two carbohydrates identified after conversion to the 1-[(S)-N-acetyl-methylbenzylamino]-1-deoxy-alditol pentaacetate derivatives [34] as D-xylose and D-glucuronic acid. In the ${ }^{1} \mathrm{H}$ NMR spectrum $\left(\mathrm{D}_{2} \mathrm{O}\right.$, Table 1$)$, five characteristic aromatic proton signals of quercetin were present [35], as well as two doublets of anomeric protons. One of these protons resonated in a relatively high field $\left(\delta_{\mathrm{H}} 4.76 \mathrm{ppm}\right)$, suggesting the presence of a disaccharide moiety and an interglycosidic linkage [35]. Signals in the ${ }^{1} \mathrm{H}$ and ${ }^{13} \mathrm{C}$ NMR spectra were assigned by 2D experiments (COSY, HMQC, HMBC) and revealed that the terminal sugar is a pentose (D-xylose). The attachment position of the disaccharide at the $\mathrm{C}-3-\mathrm{OH}$ of the aglycone was concluded from the $\mathrm{HMBC}$ cross-peak between the anomeric proton signal of $\mathrm{H}-1^{\prime \prime}\left(\delta_{\mathrm{H}} 5.29 \mathrm{ppm}\right)$ and the carbon resonance of $\mathrm{C}-3\left(\delta_{\mathrm{C}} 133.5 \mathrm{ppm}\right)$. The large coupling constants $(J=7.5$ $\mathrm{Hz}$ ) observed for both anomeric proton signals, typical of trans-diaxial conformation, suggested $\beta$-configuration of the glycosidic linkage and pyranoside form for both sugar units $[35,36]$. Two distinctive signals from $\mathrm{H}-5^{\prime \prime \prime}$ protons at $\delta_{\mathrm{H}} 3.83 \mathrm{ppm}\left(1 \mathrm{H}, d d, J_{1}=5.7\right.$ and $J_{2}=10.5 \mathrm{~Hz}$, signal of the equatorial proton $\left.\mathrm{H}-5_{\mathrm{e}}{ }^{\prime \prime \prime}\right)$ and $\delta_{\mathrm{H}} 3.19 \mathrm{ppm}\left(1 \mathrm{H}, d d, J_{1}=10.5\right.$ and $J_{2}=9.6 \mathrm{~Hz}$, signal of the axial proton $\left.\mathrm{H}-5_{\mathrm{a}}{ }^{\prime \prime \prime}\right)$ further supported the pyranoside form of D-xylose [37]. The ${ }^{13} \mathrm{C}$ NMR spectrum $\left(\mathrm{D}_{2} \mathrm{O}\right.$, Table 1$)$ showed a sizeable upfield shift $\left(\Delta \delta_{\mathrm{C}}=\right.$ $-5.6 \mathrm{ppm})$ for $\mathrm{C}-1^{\prime \prime}$ and a downfield shift $\left(\Delta \delta_{\mathrm{C}}=+3.6 \mathrm{ppm}\right)$ for $\mathrm{C}-2^{\prime \prime}$ when compared to the corresponding resonances of $\mathrm{MQ}$. These shifts located the attachment of D-xylose unit at C-2" of D-glucuronic acid [36], which was confirmed by the HMBC cross-peak between the anomeric proton signal at $\delta_{\mathrm{H}} 4.77 \mathrm{ppm}$ and a carbon resonance at $\delta_{\mathrm{C}} 80.1 \mathrm{ppm}$. Eventually, DGQ was identified as quercetin 3-O- $\beta$-D-xylopyranosyl- $(1 \rightarrow 2)-\beta$-D-glucuronopyranoside, a new natural product. The same analysis scheme was applied for DGK (Figure 3, Table 1), a minor component of MED-AP, which was identified as an analogue of DGQ, i.e., kaempferol 3-O- $\beta$-D-xylopyranosyl-( $1 \rightarrow 2)$ - $\beta$-D-glucuronopyranoside, a new natural product as well. The trivial names wintergreenoside $A$ and wintergreenoside B were proposed for DGQ and DGK, respectively. 
<smiles>O=c1c(O)c(-c2ccc(O)c([Tl])c2)oc2cc(O)cc(O)c12</smiles>

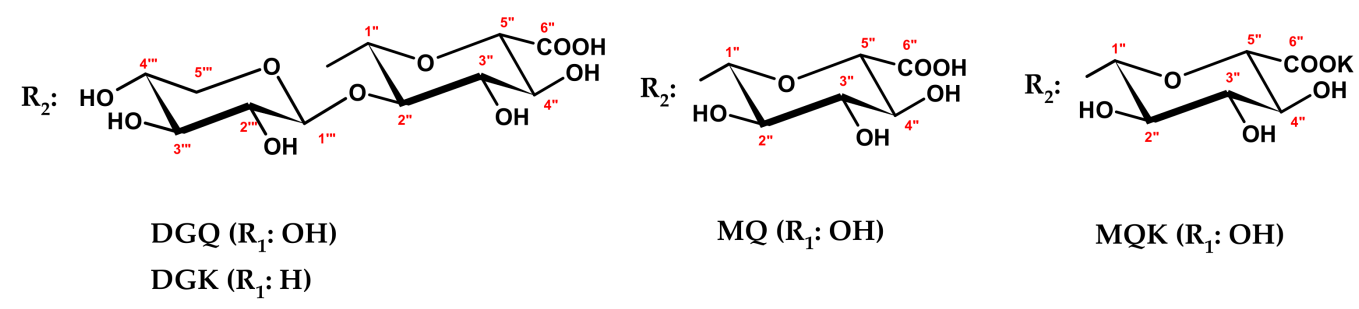

Figure 3. Structures of the isolated flavonoid compounds DGQ (wintergreenoside A), DGK (wintergreenoside $\mathrm{B}), \mathrm{MQ}$ (miquelianin), and MQK (miquelianin potassium salt). Atom numbering in red.

Compounds MQK and MQ (Figure 3) revealed in LC-PDA-ESI-MS 3 assay identical UV-vis and mass spectral profiles (Table S1) corresponding to the standard of quercetin 3-glucuronide. On the other hand, both analytes strongly differed in solubility (see above) and melting points (m.p.); in contrast to MQ (m.p. $220-223{ }^{\circ} \mathrm{C}$ ), MQK showed high m.p. values $\left(>360^{\circ} \mathrm{C}\right)$, not typical of flavonol glycosides. The HPLC-PDA analyses of the acid hydrolysates did not reveal any structural difference between MQ and MQK but confirmed the identity of the aglycone [33] and the carbohydrate unit, including its absolute configuration D [34]. In ${ }^{1} \mathrm{H}$ NMR spectra (DMSO- $d_{6}$ ), only the signals expected for quercetin and glucuronic acid were present, however, with a large downfield shift $\left(\Delta \delta_{\mathrm{H}}=+0.76 \mathrm{ppm}\right)$ for $\mathrm{H}-2^{\prime}$ and an upfield shift $\left(\Delta \delta_{\mathrm{H}}=-0.27 \mathrm{ppm}\right)$ for $\mathrm{H}-6^{\prime}$ of MQK in comparison to the corresponding resonances of $\mathrm{MQ}$. In flavonoid glycosides, such phenomenon is usually an effect of structural differences within the sugar moiety [35,36], which suggests that MQK might be an inorganic salt of MQ. Dissociation of the salt in aqueous media, including mobile phases, explains the same retention observed for both compounds in LC. The flame photometric analysis of MQK revealed the presence of potassium ions. It was supported by HR-LSI-MS assay with direct injection of the analyte (in DMSO) to the ion source, which revealed a $[\mathrm{M}-\mathrm{H}]^{-}$ion of MQK at $m / z 515.0234$, corresponding to the molecular formula $\mathrm{C}_{21} \mathrm{H}_{17} \mathrm{O}_{13} \mathrm{~K}$. The remaining structural data on the isolates, such as configuration and position of the glycosidic linkages and pyranose form of the sugar units, were deduced from 1D and 2D NMR (COSY, HMQC, HMBC) experiments. Eventually, MQK and MQ were identified as quercetin 3-O- $\beta$-D-glucuronopyranoside potassium salt and quercetin $3-O-\beta$-D-glucuronopyranoside, respectively $[38,39]$. Because of rapid hydrolysis, salts of flavonoid uronides are rarely isolated from plant materials. This is the first report on the occurrence of MQ in the form of potassium salt. Previously, its sodium salt was found in the leaves of Cyclocarya paliurus [39].

The spectroscopic (1D and 2D NMR, ESI-MS ${ }^{3}$, UV-vis, CD) and physicochemical studies (optical rotation, absolute configuration of sugar units) on the common extracts components, including GT, ECA, PB2, HY, GV (guaijaverin), IQ (isoquercitrin) and KG (kaempferol 3-O- $\beta$-D-glucuronopyranoside) enabled unequivocal confirmation of their structures $[35,37,40-42]$. 
Table 1. NMR spectral data of compound DGQ in methanol- $d_{4}$ and water- $d_{2}$ and compound DGK in methanol- $d_{4}(600 \mathrm{MHz}$ for ${ }^{1} \mathrm{H}$ and $150.9 \mathrm{MHz}$ for $\left.{ }^{13} \mathrm{C}\right){ }^{\mathrm{a}}$.

\begin{tabular}{|c|c|c|c|c|c|c|c|}
\hline \multicolumn{5}{|c|}{ DGQ } & \multicolumn{3}{|c|}{ DGK } \\
\hline Pos. ${ }^{b}$ & $\delta_{H}{ }^{c}$ & $\delta_{C}^{c}$ & $\delta_{H} d$ & $\delta_{C}^{d}$ & Pos. ${ }^{b}$ & $\delta_{H}^{c}$ & $\delta_{C}^{c}$ \\
\hline 2 & & 157.3 & & 156.8 & 2 & & 157.2 \\
\hline 3 & & 133.8 & & 133.5 & 3 & & 133.5 \\
\hline 4 & & 178.1 & & 177.4 & 4 & & 178.1 \\
\hline 5 & \multirow{3}{*}{$6.17(1 \mathrm{H}, d, J=1.9)$} & 161.5 & & 159.7 & 5 & & 161.7 \\
\hline 6 & & 98.5 & $5.89(1 \mathrm{H}, d, J=1.7)$ & 98.7 & 6 & $6.21(1 \mathrm{H}, d, J=1.9)$ & 98.4 \\
\hline 7 & & 164.4 & & 162.6 & 7 & & 164.4 \\
\hline 8 & \multirow[t]{4}{*}{$6.36(1 \mathrm{H}, d, J=1.9)$} & 93.3 & \multirow[t]{4}{*}{$5.95(1 \mathrm{H}, d, J=1.7)$} & 94.3 & 8 & $6.41(1 \mathrm{H}, d, J=1.9)$ & 93.3 \\
\hline 9 & & 156.9 & & 155.9 & 9 & & 157.2 \\
\hline 10 & & 104.4 & & 104.3 & 10 & & 104.5 \\
\hline $1^{\prime}$ & & 121.7 & & 121.5 & $1^{\prime}$ & & 121.4 \\
\hline $2^{\prime}$ & \multirow[t]{3}{*}{$7.66(1 \mathrm{H}, d, J=1.9)$} & 116.2 & \multirow[t]{3}{*}{$7.27(1 \mathrm{H}, d, J=1.7)$} & 116.4 & $2^{\prime}, 6^{\prime}$ & $8.08(2 \mathrm{H}, d, J=9.0)$ & 130.9 \\
\hline $3^{\prime}$ & & 144.6 & & 143.4 & $3^{\prime}, 5^{\prime}$ & $6.91(2 \mathrm{H}, d, J=9.0)$ & 114.8 \\
\hline $4^{\prime}$ & & 148.4 & & 147.3 & $4^{\prime}$ & & 160.1 \\
\hline $5^{\prime}$ & \multirow{2}{*}{$\begin{array}{c}6.88(1 \mathrm{H}, d, J=8.3) \\
7.59\left(1 \mathrm{H}, d d, J_{1}=1.9\right. \\
\left.J_{2}=8.3\right)\end{array}$} & 114.8 & \multirow{2}{*}{$\begin{array}{c}6.65(1 \mathrm{H}, d, J=8.9) \\
7.15\left(1 \mathrm{H}, d d, J_{1}=1.7\right. \\
\left.J_{2}=8.9\right)\end{array}$} & 115.3 & & & \\
\hline \multirow[t]{2}{*}{$6^{\prime}$} & & 122.1 & & 122.6 & & & \\
\hline & \multicolumn{7}{|c|}{ 3- $\beta$-D-glucuronopyranosyl: } \\
\hline $1^{\prime \prime}$ & \multirow{6}{*}{$\begin{array}{c}5.54(1 \mathrm{H}, d, J=7.5) \\
3.80(1 \mathrm{H}, d d, J=7.5 \\
\left.J_{2}=9.0\right) \\
3.66\left(1 \mathrm{H}, d d, J_{1}=9.0\right. \\
\left.J_{2}=9.8\right) \\
3.68\left(1 \mathrm{H}, d d, J_{1}=9.8\right. \\
\left.J_{2}=10.2\right) \\
3.74(1 \mathrm{H}, d, J=10.2)\end{array}$} & 99.8 & \multirow{6}{*}{$\begin{array}{c}5.29(1 \mathrm{H}, d, J=7.5) \\
3.82(1 \mathrm{H}, d d, J=7.5 \\
\left.J_{2}=8.3\right) \\
3.64\left(1 \mathrm{H}, d d, J_{1}=8.3\right. \\
\left.J_{2}=9.0\right) \\
3.70\left(1 \mathrm{H}, d d, J_{1}=9.0\right. \\
\left.J_{2}=9.4\right) \\
3.80(1 \mathrm{H}, d, J=9.4)\end{array}$} & 99.5 & $1^{\prime \prime}$ & $5.58(1 \mathrm{H}, d, J=7.2)$ & 99.6 \\
\hline $2^{\prime \prime}$ & & 80.1 & & 79.4 & $2^{\prime \prime}$ & $\begin{array}{c}3.74\left(1 \mathrm{H}, d d, J=7.2, J_{2}\right. \\
=9.4)\end{array}$ & 80.5 \\
\hline $3^{\prime \prime}$ & & 71.6 & & 71.5 & $3^{\prime \prime}$ & $\begin{array}{c}3.63\left(1 \mathrm{H}, d d, J_{1}=9.4\right. \\
\left.J_{2}=9.8\right)\end{array}$ & 71.5 \\
\hline $4^{\prime \prime}$ & & 76.7 & & 76.4 & $4^{\prime \prime}$ & $\begin{array}{c}3.67\left(1 \mathrm{H}, d d, J_{1}=9.8\right. \\
\left.J_{2}=10.2\right)\end{array}$ & 76.4 \\
\hline $5^{\prime \prime}$ & & 75.4 & & 76.0 & $5^{\prime \prime}$ & $3.71(1 \mathrm{H}, d, J=10.2)$ & 75.6 \\
\hline \multirow[t]{2}{*}{$6^{\prime \prime}$} & & 173.4 & & 174.5 & $6^{\prime \prime}$ & & 173.7 \\
\hline & \multicolumn{7}{|c|}{$2^{\prime \prime}-\beta$-D-xylopyranosyl: } \\
\hline $1^{\prime \prime \prime}$ & $4.77(1 \mathrm{H}, d, J=7.5)$ & 103.8 & $4.76(1 \mathrm{H}, d, J=7.5)$ & 103.1 & $1^{\prime \prime \prime}$ & $4.78(1 \mathrm{H}, d, J=6.8)$ & 103.9 \\
\hline $2^{\prime \prime \prime}$ & $\begin{array}{c}3.29\left(1 \mathrm{H}, d d, J_{1}=7.5\right. \\
\left.J_{2}=9.8\right)\end{array}$ & 73.5 & $\begin{array}{c}3.26\left(1 \mathrm{H}, d d, J_{1}=7.5\right. \\
\left.J_{2}=9.0\right)\end{array}$ & 73.3 & $2^{\prime \prime \prime}$ & $\begin{array}{c}3.37\left(1 \mathrm{H}, d d, J_{1}=6.8\right. \\
\left.J_{2}=8.3\right)\end{array}$ & 73.5 \\
\hline $3^{\prime \prime \prime}$ & $\begin{array}{c}3.36\left(1 \mathrm{H}, d d, J_{1}=9.8\right. \\
\left.J_{2}=9.8\right)\end{array}$ & 75.7 & $\begin{array}{c}3.43\left(1 \mathrm{H}, d d, J_{1}=9.0\right. \\
\left.J_{2}=9.0\right)\end{array}$ & 75.5 & $3^{\prime \prime \prime}$ & $\begin{array}{c}3.40\left(1 \mathrm{H}, d d, J_{1}=8.3\right. \\
\left.J_{2}=8.7\right)\end{array}$ & 75.6 \\
\hline $4^{\prime \prime \prime}$ & $\begin{array}{c}3.48\left(1 \mathrm{H}, d d d, J_{1}=\right. \\
\left.5.3, J_{2}=9.8, J_{3}=10.2\right)\end{array}$ & 69.6 & $\begin{array}{c}3.54\left(1 \mathrm{H}, d d d, J_{1}=\right. \\
\left.5.7, J_{2}=9.0, J_{3}=9.6\right)\end{array}$ & 69.3 & $4^{\prime \prime \prime}$ & $\begin{array}{c}3.53\left(1 \mathrm{H}, d d d, J_{1}=4.9\right. \\
\left.J_{2}=8.3, J_{3}=8.7\right)\end{array}$ & 69.6 \\
\hline \multirow[t]{2}{*}{$5^{\prime \prime \prime}$} & \multirow{2}{*}{$\begin{array}{c}\left.5.3, J_{2}=9.8, J_{3}=10.2\right) \\
3.17\left(1 \mathrm{H}, d d, J_{1}=\right. \\
10.2, J_{2}=11.7 \\
\left.\mathrm{H}-5_{\mathrm{a}}{ }^{\prime \prime \prime}\right) \\
3.84\left(1 \mathrm{H}, d d, J_{1}=5.3\right. \\
\left.J_{2}=11.7, \mathrm{H}-5_{\mathrm{e}}{ }^{\prime \prime \prime}\right)\end{array}$} & 65.2 & $\begin{array}{c}3.19\left(1 \mathrm{H}, d d, J_{1}=9.6\right. \\
\left.J_{2}=10.5, \mathrm{H}-5_{\mathrm{a}}{ }^{\prime \prime \prime}\right)\end{array}$ & \multirow[t]{2}{*}{65.1} & \multirow[t]{2}{*}{$5^{\prime \prime \prime}$} & $\begin{array}{c}3.23\left(1 \mathrm{H}, d d, J_{1}=8.7\right. \\
\left.J_{2}=11.3, \mathrm{H}-5_{\mathrm{a}}{ }^{\prime \prime \prime}\right)\end{array}$ & 65.2 \\
\hline & & & $\begin{array}{c}3.83\left(1 \mathrm{H}, d d, J_{1}=5.7\right. \\
\left.J_{2}=10.5, \mathrm{H}-5 \mathrm{e}^{\prime \prime \prime}\right)\end{array}$ & & & $\begin{array}{c}3.94\left(1 \mathrm{H}, d d, J_{1}=4.9\right. \\
\left.J_{2}=11.3, \mathrm{H}-5 \mathrm{e}^{\prime \prime \prime}\right)\end{array}$ & \\
\hline
\end{tabular}

${ }^{a}$ Data acquired with TMS as the internal standard, $\delta$ in ppm. Multiplicities and coupling constants (in Hz) are given in parentheses. Assignments confirmed by ${ }^{1} \mathrm{H}-{ }^{1} \mathrm{H}$ COSY, HMQC, and HMBC experiments. ${ }^{b}$ For trivial atom numbering, see the chemical formula of DGQ (wintergreenoside A) and DGK (wintergreenoside B) (Figure 3). ${ }^{\mathrm{c}}$ Data acquired in methanol- $d_{4} \cdot{ }^{\mathrm{d}}$ Data acquired in water- $d_{2}$.

\subsection{Biological Activity of the Selected Gaultheria Polyphenols}

The pre-selected compounds were subjected to biological activity tests in vitro to confirm their usefulness as active markers of G. procumbens aerial parts. However, among three position isomers of monocaffeoylquinic acid (CHA, NCHA, CCHA), only CHA was tested as a model analyte for the group. The tests were chosen according to the accumulated pharmacological data on Gaultheria plants to reflect some of the best recognised mechanisms of their anti-inflammatory and antioxidant activities [10-13,18-21]. They included: reducing capacity (FRAP), direct scavenging of $\mathrm{O}_{2}{ }^{\bullet-}$ as a primary ROS generated by immune cells in inflammatory conditions, direct inhibition of pro-inflammatory enzymes (COX-2, HYAL), 
and modulation of pro-inflammatory and pro-oxidant functions of human neutrophils ex vivo (influence on the release of ROS, IL-1 $\beta$, TNF- $\alpha$, and ELA-2).

As shown in Table 2 and Figure 4, the investigated compounds revealed concentrationdependent effects in all models but varied significantly in capacity, depending on the test. The most significant differences were observed in non-cellular models. In comparison to the standards (Trolox, ascorbic acid), all analytes except GT revealed potent antioxidant activity, mostly surpassing that of the standards, with the most substantial effects for all procyanidins (ECA, PB2, CB1) in the $\mathrm{O}_{2}{ }^{\bullet-}$ scavenging assay, and a flavonol aglycone (QU) and oligomeric procyanidins (PB2, CB1) in the FRAP test (Table 2). The weak capacity observed for GT was not surprising as it lacks free phenolic groups, which are crucial for the direct antioxidant activity of polyphenols [43]. In the case of other analytes, also further structural elements, especially the glycosylation and polymerisation degree, influenced their activity. As the tests were based on different mechanisms (hydrogen atom transfer, HAT, and single electron transfer, SET, respectively), there is no significant correlation between the activity parameters $(r=0.5107, p>0.05)$, which might suggest advantageous complementary antioxidant effects of individual polyphenols in complex oxidant systems.

Table 2. Anti-inflammatory and antioxidant activity of the selected compounds.

\begin{tabular}{|c|c|c|c|c|}
\hline \multirow{3}{*}{ Analyte } & \multicolumn{2}{|c|}{ Anti-Inflammatory Activity } & \multicolumn{2}{|c|}{ Antioxidant Activity } \\
\hline & COX-2 & HYAL & $\mathrm{O}_{2} \bullet-$ & FRAP \\
\hline & $\mathrm{IC}_{50}(\mathrm{mM})^{\mathrm{a}}$ & $\mathrm{IC}_{50}(\mu \mathrm{M})^{\mathrm{a}}$ & $S C_{50}(\mu M)^{b}$ & $\mathrm{~mol} \mathrm{Fe}^{2+} / \mathrm{mol}^{\mathrm{c}}$ \\
\hline QU & $1.56 \pm 0.05^{\mathrm{E}}$ & $101.84 \pm 6.09^{F}$ & $25.08 \pm 0.69^{\mathrm{E}}$ & $14.23 \pm 0.18^{G}$ \\
\hline $\mathrm{MQ}$ & $1.29 \pm 0.05^{C}$ & $98.15 \pm 4.41^{\mathrm{E}, \mathrm{F}}$ & $32.55 \pm 2.19 \mathrm{G}$ & $9.24 \pm 0.06^{\mathrm{E}}$ \\
\hline DGQ & $1.44 \pm 0.06^{\mathrm{D}}$ & $98.08 \pm 2.31 \mathrm{E}$ & $18.00 \pm 1.26^{\mathrm{D}}$ & $6.39 \pm 0.14^{\mathrm{D}}$ \\
\hline $\mathrm{ECA}$ & $1.62 \pm 0.07 \mathrm{E}$ & $81.85 \pm 3.96^{\mathrm{D}}$ & $7.89 \pm 0.41 \mathrm{C}$ & $10.39 \pm 0.27^{\mathrm{F}}$ \\
\hline PB2 & $1.43 \pm 0.06^{\mathrm{D}}$ & $37.42 \pm 1.78^{\mathrm{B}}$ & $6.26 \pm 0.09^{B}$ & $17.11 \pm 0.06^{\mathrm{I}}$ \\
\hline CB1 & $1.56 \pm 0.07^{\mathrm{E}}$ & $37.69 \pm 0.80^{\mathrm{B}}$ & $5.31 \pm 0.12^{\mathrm{A}}$ & $16.30 \pm 0.10^{\mathrm{H}}$ \\
\hline $\mathrm{CHA}$ & $2.86 \pm 0.13^{\mathrm{F}}$ & $80.69 \pm 3.42^{\mathrm{D}}$ & $19.73 \pm 0.42^{\mathrm{D}}$ & $9.06 \pm 0.18^{\mathrm{E}}$ \\
\hline GT & $0.78 \pm 0.03^{\mathrm{B}}$ & $64.02 \pm 2.87^{C}$ & $1012.00 \pm 31.72^{\mathrm{I}}$ & $0.29 \pm 0.02 \mathrm{~A}$ \\
\hline IND & $0.50 \pm 0.02^{\mathrm{A}}$ & $35.69 \pm 5.34^{\mathrm{A}}$ & - & - \\
\hline DEX & $1.29 \pm 0.04 \mathrm{C}$ & $36.13 \pm 2.68^{\mathrm{A}, \mathrm{B}}$ & - & - \\
\hline $\mathrm{TX}$ & - & - & $540.33 \pm 4.04^{\mathrm{H}}$ & $2.98 \pm 0.06^{\mathrm{B}}$ \\
\hline AA & - & - & $29.87 \pm 0.51^{\mathrm{F}}$ & $3.97 \pm 0.02 \mathrm{C}$ \\
\hline
\end{tabular}

${ }^{\mathrm{a}} \mathrm{IC}_{50}$, half-maximal inhibitory concentration (amount of an analyte needed for $50 \%$ inhibition of enzyme activity); ${ }^{\mathrm{b}} \mathrm{SC}_{50}$, half-maximal scavenging efficiency (amount of antioxidant needed to decrease the initial concentration of the oxidant by $50 \%$ ); ${ }^{c}$ antioxidant activity expressed in mol of ferrous ions $\left(\mathrm{Fe}^{2+}\right)$ produced by $1 \mathrm{~mol}$ of an analyte. Analytes: $\mathrm{QU}$, quercetin; $\mathrm{MQ}$, miquelianin; DGQ, wintergreenoside A; ECA, (-)-epicatechin; PB2, procyanidin B2; CB1, cinnamtannin B-1; CHA, chlorogenic acid; GT, gaultherin. Positive controls: AA, ascorbic acid; DEX, dexamethasone; IND, indomethacin; TX, Trolox. Results presented as mean values $\pm \operatorname{SD}(n=3)$. For each parameter, different capital letters given in parentheses (A-I) indicate significant differences $(p<0.05)$.

Similar relationships were observed on the direct inhibition of COX-2, except for relatively lower differences between individual compounds and the potent activity of GT (Table 2). As a derivative of salicylic acid, GT is among the most effective natural COX-2 inhibitors [44]. Indeed, its IC 50 value fell in between that of two synthetic anti-inflammatory drugs, indomethacin and dexamethasone (Table 2) that might confirm the high potential of GT to treat inflammation. On the other hand, the activity of other tested polyphenols, except for CHA, was only at most twice as weak. Interestingly, the $\mathrm{IC}_{50}$ values for COX-2 inhibition were similar for all tested flavonoids and procyanidins. In contrast, the inhibitory activity of the analytes towards HYAL varied in a broader range. Oligomeric procyanidins (PB2, CB1) turned out to be the most potent, and their $\mathrm{IC}_{50}$ values did not differ from those of dexamethasone. The HYAL-inhibitory activity of GT was also noticeable and intermediate between the oligomeric procyanidins and all other polyphenols, including flavonoids, ECA, and CHA. 
(A)

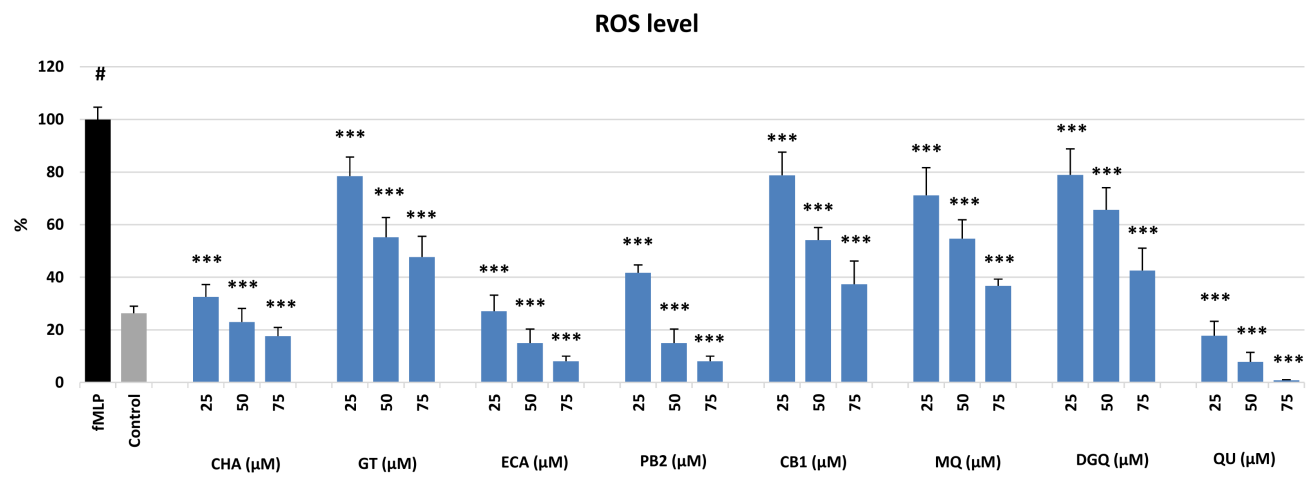

(B)

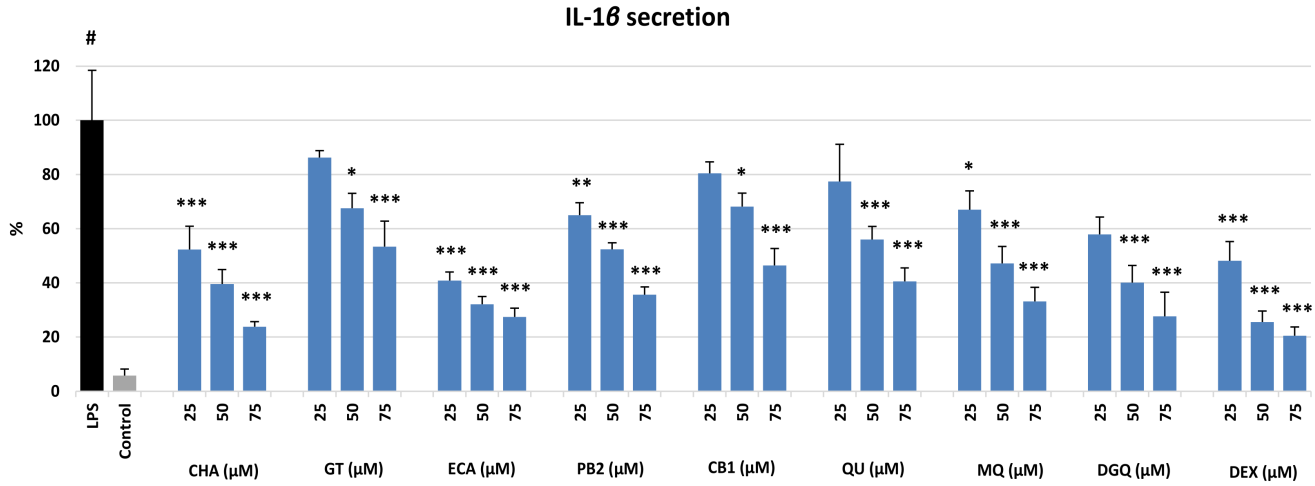

(C)

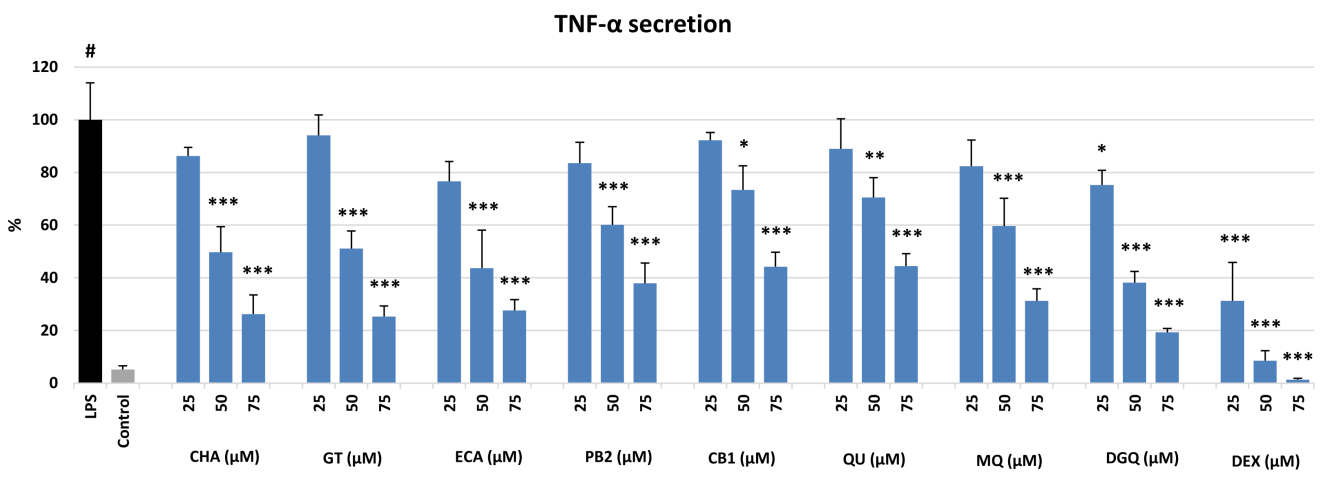

(D)

Elastase secretion

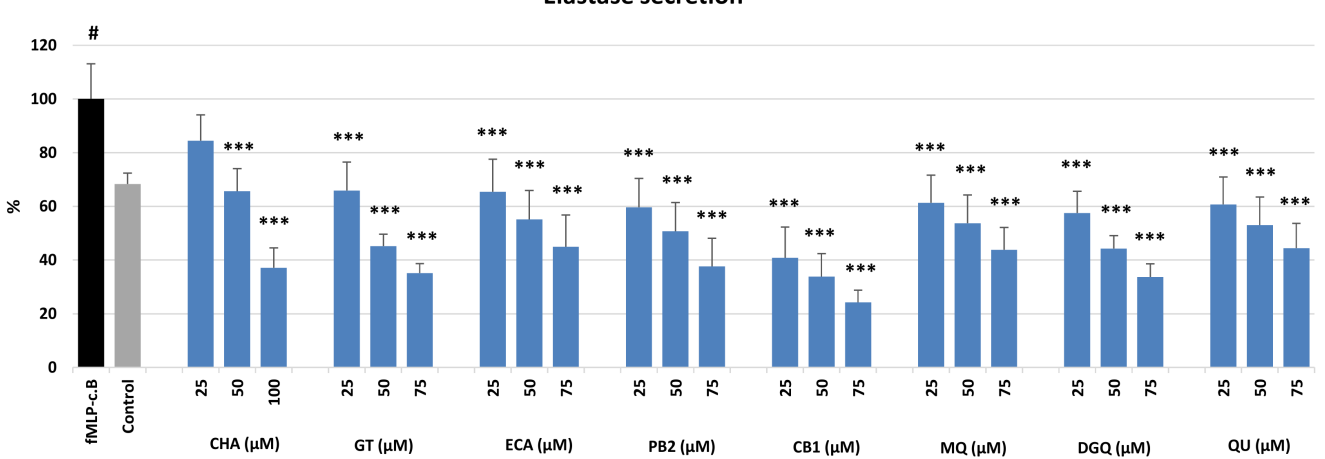

Figure 4. Effect of the selected compounds at 25-75 $\mu \mathrm{M}$ on: (A) ROS production and secretion of (B) IL-1 $\beta$, (C) TNF- $\alpha$, and (D) ELA-2 by stimulated human neutrophils. Data expressed as means \pm SD of three independent experiments performed with cells isolated from five independent donors. Statistical significance: \# $p<0.001$ compared to the non-stimulated control; ${ }^{*} p<0.05,{ }^{* *} p<0.01,{ }^{* * *} p<0.001$ compared to the stimulated control. Analytes: QU, quercetin; MQ, miquelianin; DGQ, wintergreenoside A; ECA, (-)-epicatechin; PB2, procyanidin B2; CB1, cinnamtannin B-1; CHA, chlorogenic acid; GT, gaultherin. Positive controls: (A,D) QU, quercetin; $(B, C) D E X$, dexamethasone. 
On the other hand, these polyphenols were only up to 1.5-fold less active than GT. As COX-2 and HYAL are involved in the progression of inflammation and therapeutic targets in inflammation-related disorders $[45,46]$, the obtained results might indicate the substantial contribution of all of the assayed compounds to the anti-inflammatory activity of the Gaultheria extracts.

As shown in Figure 4, all analytes also revealed antioxidant and anti-inflammatory effects at a cellular level and significantly influenced the pro-oxidant and pro-inflammatory functions of human neutrophils ex vivo with no effect on their viability (Figure S2). Neutrophils are the most abundant immune cells in human blood; in response to infection or tissue injury, they release a large amount of ROS and pro-inflammatory mediators, orchestrating the inflammatory process [47]. All analytes at 25-75 $\mu \mathrm{M}$ inhibited the oxidative burst of $f$ MLP-stimulated neutrophils and down-regulated the ROS levels by up to 22-99\%, depending on the compound and level (Figure 4A). The most active were QU (a positive control in this test), ECA, CHA, and PB2. Interestingly, the activity of GT did not differ significantly from that of flavonoid glycosides (MQ, DGQ) and a procyanidin trimer (CB1), which confirmed the previous reports on the potent cellular antioxidant effects of salicylates $[10,18,21]$. The mechanistic studies revealed that these effects are indirect and connected with inhibiting the MAPK/NF-kB pathway $[19,21]$.

Apart from the down-regulation of the oxidative burst, all analytes at the whole concentration range significantly inhibited $(p<0.05)$ the release of IL-1 $\beta$ (Figure $4 \mathrm{~B}$ ) and TNF- $\alpha$ (Figure $4 \mathrm{C}$ ), two prime agonists of neutrophils and pleiotropic cytokines modulating the gene expression and secretion of numerous other pro-inflammatory factors [48,49], and ELA-2 (Figure 4D), a tissue remodelling enzyme involved in the progression of inflammation [50]. The flavonoid diglycoside (DGQ), ECA, and CHA regulated the levels of IL-1 $\beta$ most substantially by up to $73-76 \%$ at $75 \mu \mathrm{M}$, but other compounds were also influential. For instance, the weakest activity of GT meant $47 \%$ inhibition. Similar effects were revealed in the case of TNF- $\alpha$ release, except that GT was this time among the most active analytes (DGQ, ECA, CHA), exhibiting an inhibition rate up to $75-81 \%$ at $75 \mu \mathrm{M}$. The relatively smallest differences between the analytes were observed for the ELA-2 release; however, CB1 was clearly the most potent. It down-regulated the enzyme secretion by up to $76 \%$ at $75 \mu \mathrm{M}$. Nevertheless, the cellular tests indicated that all analytes might be considered active markers of $G$. procumbens, and their contribution to the biological effects of the extracts might depend mainly on their concentration.

\subsection{Development, Validation, and Application of the HPLC-PDA Method for Quantitative Purposes}

The chromatographic procedure was developed to separate the selected 11 constituents of the G. procumbens extracts (Figure 5A) in a significantly shorter time than used in the qualitative UHPLC profiling (80 min including equilibration). An RP-18 fused-core column was chosen for the task due to its high performance in HPLC systems [51]. Eventually, a linear gradient of acetonitrile in acidified water (Table 3$)$, column temperature $\left(18^{\circ} \mathrm{C}\right)$, and flow rate $(1.4 \mathrm{~mL} / \mathrm{min})$ were optimised to achieve satisfactory separation of the analytes within 35 min (including equilibration).

Table 3. The optimised elution profile.

\begin{tabular}{ccc}
\hline Time (min) & $\begin{array}{c}\text { Solvent A (0.5\% Aqueous Solution of } \\
\text { Orthophosphoric Acid, } \boldsymbol{w} / \boldsymbol{v}, \mathbf{\%})\end{array}$ & Solvent B (Acetonitrile, \%) \\
\hline $0-1.0$ & 94 (isocratic elution) & 6 (isocratic elution) \\
$1.0-8.5$ & $94 \rightarrow 86$ (linear gradient) & $6 \rightarrow 14$ (linear gradient) \\
$8.5-15.0$ & $86 \rightarrow 84$ (linear gradient) & $14 \rightarrow 16$ (linear gradient) \\
$15.0-23.0$ & $84 \rightarrow 50$ (linear gradient) & $16 \rightarrow 50$ (linear gradient) \\
$23.0-24.0$ & 50 (isocratic elution) & 50 (isocratic elution) \\
$24.0-25.0$ & $50 \rightarrow 94$ (linear gradient, return to the initial conditions) & $50 \rightarrow 6$ (linear gradient, return to the initial conditions) \\
$25.0-30.0$ & 94 (equilibration) & 6 (equilibration) \\
\hline
\end{tabular}



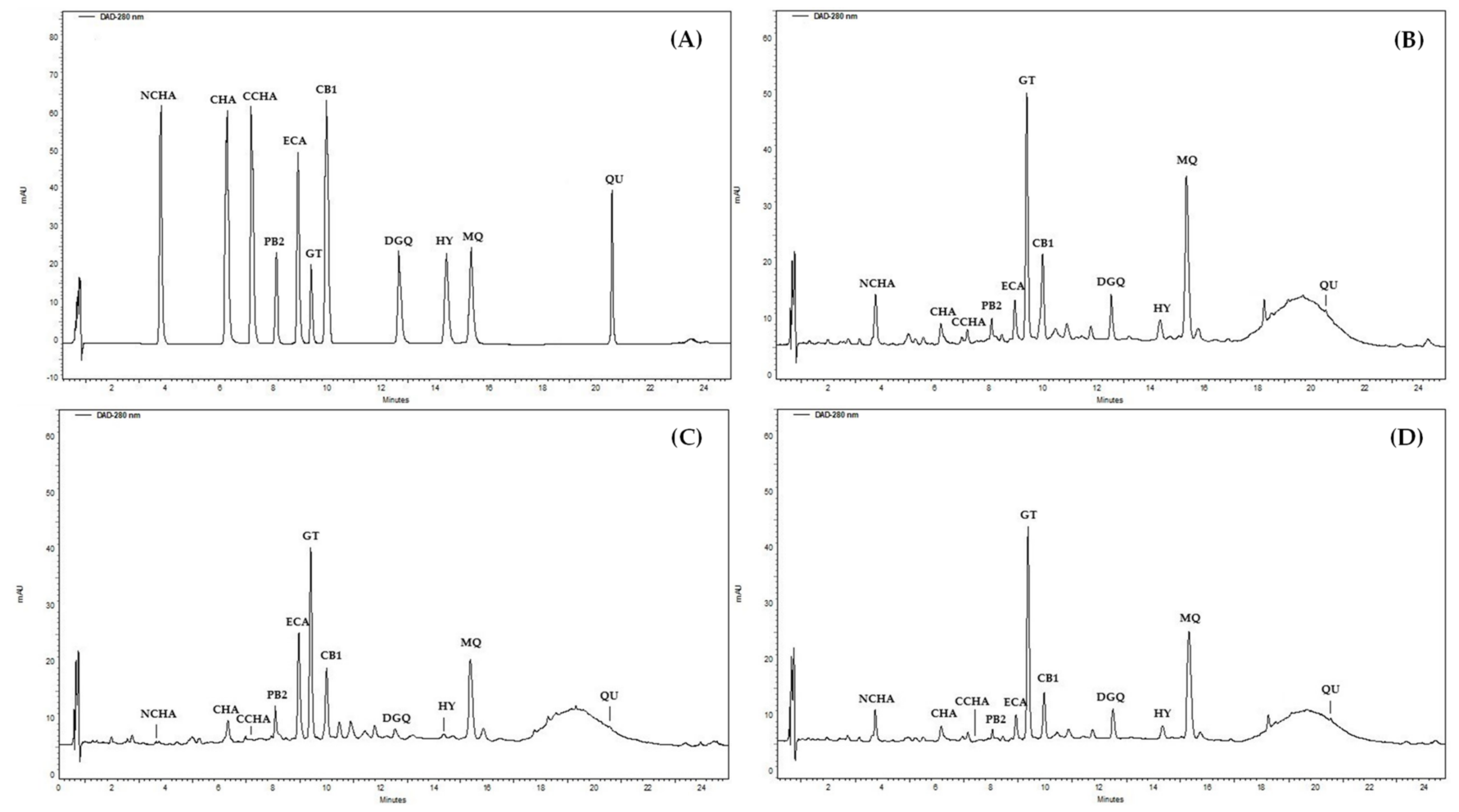

Figure 5. Representative HPLC-PDA chromatograms at $280 \mathrm{~nm}$ of: (A) standards, and (B-D) the methanol-water (75:25, $v / v$ ) extracts (ME) of leaves (B), stems (C), and the aerial parts (D) of G. procumbens separated under optimised conditions. Analytes: QU, quercetin; MQ, miquelianin; HY, hyperoside; DGQ, wintergreenoside A; ECA, (-)-epicatechin; PB2, procyanidin B2; CB1, cinnamtannin B-1; NCHA, neochlorogenic acid; CHA, chlorogenic acid; CCHA, cryptochlorogenic acid; GT, gaultherin.

The proposed method was validated by determining the selectivity, linearity, precision, and accuracy according to the International Council for Harmonization (ICH) Guidance for Industry [52]. The adequate selectivity was demonstrated in the real samples (Figure 5B-D): the target peaks eluted as pure bands and were satisfactorily separated from the matrix. The linearity was confirmed in the whole concentration range, including limits of quantitation (LOQs), with $r>0.9994$ (Table 4). The statistical significance of the regression equations was verified in the $F$-test $(p<0.05)$. The low limits of detection (LODs, $0.11-0.55 \mu \mathrm{g} / \mathrm{mL}, 0.53-2.76 \mathrm{ng})$ and LOQs $(0.36-1.84 \mu \mathrm{g} / \mathrm{mL}, 1.79-9.19 \mathrm{ng})$ demonstrated the high sensitivity of the method (Table 4$)$. The RSD values measured for peak area for intra-day (0.39-1.93\%) and inter-day precision (2.74-4.12\%) did not exceed the predicted values (2.19-4.38\%), calculated using the Horvitz equation according to the AOAC International [53], which indicated the adequate precision (Table 5). In the accuracy studies, the recoveries were within the range of $95.45-101.16 \%$ (Table 5), thus within the acceptance limits (92-105\%) [54]. Finally, the proposed method is superior to the previously published approach [17] in terms of the range of the tested analytes, chromatographic performance, and validation parameters.

The applicability of the method to the intended use was demonstrated by determining the levels of the target compounds in the aerial part, leaf, and stem extracts of G. procumbens (Table S2). The crude extracts and the concentrated fractions obtained for preparative purposes were analysed to cover a wide range of concentrations and relative ratios between the analytes.

Their total content in the crude extracts varied in a narrow range of $181.04-192.78 \mathrm{mg} / \mathrm{g}$, but it rose to $384.48 \mathrm{mg} / \mathrm{g}$ in the fractions (EAF-AP), confirming that the selected model compounds form a large part of the extracts. 
Table 4. Validation data for the proposed HPLC-PDA method.

\begin{tabular}{|c|c|c|c|c|c|c|c|c|}
\hline \multirow[b]{2}{*}{ Analyte } & \multirow[b]{2}{*}{$\begin{array}{l}\mathbf{t}_{R} \pm \mathrm{SD} \\
\quad(\mathrm{min})\end{array}$} & \multirow[b]{2}{*}{$\lambda(\mathbf{n m})$} & \multicolumn{4}{|c|}{ Linearity } & \multicolumn{2}{|c|}{ Sensitivity } \\
\hline & & & $\begin{array}{c}\text { Linear } \\
\text { Regression }\end{array}$ & $r$ & $\begin{array}{c}\text { Linear Range } \\
(\mu \mathrm{g} / \mathrm{mL})\end{array}$ & $F$-Test & $\begin{array}{c}\text { LOD } \\
(\mu \mathrm{g} / \mathrm{mL})\end{array}$ & $\begin{array}{c}\mathrm{LOQ} \\
(\mu \mathrm{g} / \mathrm{mL})\end{array}$ \\
\hline NCHA & $3.86 \pm 0.02$ & 325 & $y=45,336.38 x$ & 0.9992 & $0.37-122.4$ & 5072.1 & 0.122 & 0.407 \\
\hline $\mathrm{CHA}$ & $6.29 \pm 0.02$ & 325 & $y=45,621.24 x$ & 0.9993 & $0.32-106.6$ & 5430.2 & 0.107 & 0.357 \\
\hline CCHA & $7.29 \pm 0.02$ & 325 & $y=43,237.18 x$ & 0.9994 & $0.36-120.5$ & 5753.8 & 0.121 & 0.403 \\
\hline PB2 & $8.20 \pm 0.02$ & 280 & $y=14,435.01 x$ & 0.9993 & $0.85-56.6$ & 9200.8 & 0.283 & 0.943 \\
\hline ECA & $9.07 \pm 0.02$ & 280 & $y=12,576.01 x$ & 0.9995 & $0.81-53.7$ & $12,206.4$ & 0.269 & 0.897 \\
\hline GT & $9.51 \pm 0.02$ & 285 & $y=4501.262 x$ & 0.9995 & $1.65-551.0$ & $13,779.8$ & 0.551 & 1.837 \\
\hline CB1 & $10.12 \pm 0.02$ & 280 & $y=13,183.35 x$ & 0.9998 & $0.89-59.6$ & $30,390.9$ & 0.298 & 0.993 \\
\hline DGQ & $12.69 \pm 0.02$ & 350 & $y=25,690.20 x$ & 0.9990 & $0.83-55.4$ & 6606.6 & 0.277 & 0.923 \\
\hline HY & $14.52 \pm 0.03$ & 350 & $y=29,715.40 x$ & 0.9994 & $0.85-56.5$ & $10,507.6$ & 0.283 & 0.943 \\
\hline MQ & $15.51 \pm 0.03$ & 350 & $y=32,178.87 x$ & 0.9995 & $0.64-84.8$ & $13,826.4$ & 0.212 & 0.707 \\
\hline$\widehat{Q U}$ & $20.67 \pm 0.01$ & 370 & $y=62,719.28 x$ & 0.9995 & $0.41-55.3$ & $14,002.5$ & 0.138 & 0.460 \\
\hline
\end{tabular}

$\mathrm{t}_{R}$, retention time; $\lambda$, detection wavelength; $y$, peak area; $x$, concentration of standard in $\mu \mathrm{g} / \mathrm{mL}$; $F$-test, value of the statistical Fisher variance ratio for the experimental data. LOD, limit of detection. LOQ, limit of quantification. Analytes: QU, quercetin; $M Q$, miquelianin; HY, hyperoside; DGQ, wintergreenoside A; ECA, (-)-epicatechin; PB2, procyanidin B2; CB1, cinnamtannin B-1; NCHA, neochlorogenic acid; CHA, chlorogenic acid; CCHA, cryptochlorogenic acid; GT, gaultherin.

Table 5. Precision and accuracy data for the proposed HPLC-PDA method.

\begin{tabular}{|c|c|c|c|c|c|}
\hline \multirow{3}{*}{ Analyte } & \multicolumn{4}{|c|}{ Precision (RSD, \%) } & \multirow{3}{*}{ Mean Recovery \pm SD $(\%)$} \\
\hline & \multicolumn{2}{|c|}{ Intra-Day Variability } & \multicolumn{2}{|c|}{ Inter-Day Variability } & \\
\hline & $\mathbf{t}_{R}$ (Retention Time) & Peak Area & $\mathbf{t}_{R}$ (Retention Time) & Peak Area & \\
\hline NCHA & 0.41 & 0.39 & 1.72 & 3.47 & $99.45 \pm 2.16$ \\
\hline CHA & 0.30 & 0.84 & 1.65 & 3.65 & $100.00 \pm 3.25$ \\
\hline CCHA & 0.27 & 0.85 & 1.48 & 3.53 & $99.23 \pm 3.33$ \\
\hline PB2 & 0.28 & 1.58 & 1.78 & 3.88 & $99.15 \pm 2.97$ \\
\hline ECA & 0.27 & 1.27 & 1.55 & 3.73 & $98.92 \pm 2.55$ \\
\hline GT & 0.21 & 0.34 & 1.33 & 2.74 & $101.16 \pm 3.46$ \\
\hline CB1 & 0.32 & 1.93 & 1.47 & 3.76 & $98.78 \pm 3.77$ \\
\hline DGQ & 0.24 & 1.32 & 1.35 & 3.85 & $99.86 \pm 2.32$ \\
\hline $\mathrm{HY}$ & 0.26 & 1.53 & 1.54 & 3.77 & $99.91 \pm 2.15$ \\
\hline MQ & 0.28 & 1.46 & 1.62 & 3.54 & $99.33 \pm 2.73$ \\
\hline QU & 0.09 & 1.32 & 1.73 & 4.12 & $99.65 \pm 2.49$ \\
\hline
\end{tabular}

Analytes: QU, quercetin; MQ, miquelianin; HY, hyperoside; DGQ, wintergreenoside A; ECA, (-)-epicatechin; PB2, procyanidin B2; CB1, cinnamtannin B-1; NCHA, neochlorogenic acid; CHA, chlorogenic acid; CCHA, cryptochlorogenic acid; GT, gaultherin.

Moreover, the increase in the QU content from $0.19 \mathrm{mg} / \mathrm{g} \mathrm{dw}$ in ME-AP to $0.48 \mathrm{mg} / \mathrm{g}$ $\mathrm{dw}$ in MED-AP and 5.36-8.68 mg/g dw in its organic fractions confirmed that QU might indeed be a suitable marker of the hydrolytic degradation of the extracts during processing or storage. Considering the demonstrated activity of the selected compounds, they might be recommended as standardisation markers for the quality control of the analysed extracts.

\section{Materials and Methods}

\subsection{Reagents and Standards}

HPLC-grade reagents and standards, such as quercetin dihydrate (QU); hyperoside (HY; quercetin 3-O- $\beta$-D-galactopyranoside); miquelianin (MQ; quercetin 3-O- $\beta$-Dglucuronopyranoside); guaijaverin (GV; quercetin 3-O- $\alpha$-L-arabinopyranoside); isoquercitrin (IQ; quercetin 3-O- $\beta$-D-glucopyranoside); (-)-epicatechin (ECA); kaempferol 3-O- $\beta$-Dglucuronopyranoside $(\mathrm{KG})$; procyanidin $\mathrm{B} 2$ (PB2; epicatechin- $(4 \beta \rightarrow 8)$-epicatechin); 3$\mathrm{O}$-caffeoyl-quinic acid (NCHA, neochlorogenic acid); 4-O-caffeoylquinic acid (CCHA, cryptochlorogenic acid); 5-O-caffeoylquinic acid hemihydrate (CHA, chlorogenic acid); bovine testis hyaluronidase; bovine serum albumin; hyaluronic acid; ascorbic acid (AA); dexamethasone (DEX); indomethacin (IND); ( \pm )-6-hydroxy-2,2,7,8-tetramethylchroman- 
2-carboxylic acid (Trolox $\left.{ }^{\circledR}, T X\right) ; N$-formyl-L-methionyl-L-leucyl-L-phenylalanine ( $f$ MLP); lipopolysaccharide (LPS) from Escherichia coli; $N$-succinyl-alanine-alanine-valine $p$-nitroanilide (SAAVNA); formic acid; acetic acid, and orthophosphoric acid were of HPLC-grade and purchased from Merck (Darmstadt, Germany). HPLC-grade solvents (acetonitrile, methanol, hexane, isopropanol, and water) were from Avantor Performance Materials (Gliwice, Poland). Solvents used to extract the plant material and purify the compounds were from Chempur (Piekary Ślaskie, Poland) and were of analytical grade.

\subsection{Plant Material and Extraction}

Leaves, stems, and aerial parts of G. procumbens L. were collected in October 2019 in the gardening centre of Ericaceae plants, Gospodarstwo Szkolkarskie Jan Cieplucha ( $54^{\circ} 44^{\prime}$ $\mathrm{N}, 19^{\circ} 18^{\prime} \mathrm{E}$ ), Konstantynow Lodzki (Poland), where the plants grew in an open area. The plant origin and authentication were described previously [11]. The voucher specimens (KFG/HB/19001-GPRO-LEAF, KFG/HB/19001-GPRO-STEM, KFG/HB/19001-GPROAP) were deposited in the Medicinal Plant Garden, Medical University of Lodz (Poland). Samples of the plant material were air-dried at $35{ }^{\circ} \mathrm{C}$ in the shade with air humidity of about $40 \%$, powdered with an electric grinder, and sieved through a $\varnothing 0.315 \mathrm{~mm}$ sieve.

The powdered plant material (100 g each) was subjected to static solvent extraction and refluxed thrice ( $2 \mathrm{~h}$ each time) with $300 \mathrm{~mL}$ of methanol-water $(75: 25, v / v)$. Then, the combined extracts were evaporated at $40{ }^{\circ} \mathrm{C}$ (in vacuo) and next lyophilised (Alpha 1-2/LD Plus freeze dryer, Christ, Osterode am Harz, Germany) to provide the methanol-water extracts (ME) of the leaves (ME-L, $37.2 \mathrm{~g} \mathrm{dw}$ ), stems (ME-S, $45.7 \mathrm{~g} \mathrm{dw}$ ), and aerial parts (ME-AP, $42.3 \mathrm{~g} \mathrm{dw}$ ), respectively.

For isolation of polyphenols, the sample of the aerial parts $(2730 \mathrm{~g})$ was pre-extracted with chloroform in Soxhlet apparatus $(1 \mathrm{~L}, 48 \mathrm{~h})$ to remove lipoidal components and refluxed exhaustively with methanol-water $(75: 25, v / v)$ to obtain the defatted methanolwater extract (MED-AP, 743.8 g dw). Eventually, MED-AP was fractionated into the diethyl ether fraction (DEF-AP, $25.3 \mathrm{~g} \mathrm{dw}$ ), ethyl acetate fraction (EAF-AP, $30.5 \mathrm{~g} \mathrm{dw}$ ), $n$-butanol fraction (BF-AP, $173.1 \mathrm{~g} \mathrm{dw}$ ), and water fraction (WF-AP, $419.9 \mathrm{~g} \mathrm{dw}$ ) according to Michel et al. [13]. The obtained extract and fractions, except WF-AP, were evaporated in vacuo, and the water-containing ones (MED-AP, BF-AP, WF-AP) were next lyophilised. The extraction yields were calculated per dry weight $(\mathrm{dw})$ of the plant material.

\subsection{UHPLC-PDA-ESI-MS ${ }^{3}$ Profiling}

The profile of ME-AP was analysed by UHPLC-PDA-ESI-MS ${ }^{3}$ according to Michel et al. [13] using the same equipment and chromatographic procedure. Before the analysis, samples of the tested extracts $(10-40 \mathrm{mg}$ ) were dissolved in $10 \mathrm{~mL}$ of methanolwater $(75: 25, v / v)$ and filtered through a PTFE syringe filter $(25 \mathrm{~mm}, 0.2 \mu \mathrm{m}$, Ahlstrom, Helsinki, Finland).

\subsection{Isolation of Phenolic Compounds \\ 3.4.1. Preparative HPLC-PDA}

The experiments were performed on preparative Waters 2545 binary system (Milford, MA, USA) equipped with an autosampler, a Waters 2998 PDA detector, and a preparative Zorbax SB C18 column $(5.0 \mu \mathrm{m}, 150 \mathrm{~mm} \times 21.2 \mathrm{~mm}$; Agilent Technologies, Santa Clara, CA, USA). The mobile phase consisted of solvent A (water-formic acid, 100:0.1, $v / v$ ) and solvent B (acetonitrile-formic acid, 100:0.1, v/v). The elution profile was as follows: $0-30 \mathrm{~min}$, $5-25.5 \%$ B $(v / v) ; 30-35 \mathrm{~min}, 25.5-5 \%$ B (equilibration). All gradients were linear. The separation was carried out at room temperature $\left(20-25^{\circ} \mathrm{C}\right)$, the flow rate was $7 \mathrm{~mL} / \mathrm{min}$, and the injection volume was $250 \mu \mathrm{L}$. Before the isolation, the phenolic fractions (portions of $50 \mathrm{mg}$ ) were dissolved in the mobile phase $(1 \mathrm{~mL})$ and filtered through a PTFE syringe filter $(25 \mathrm{~mm}, 0.2 \mu \mathrm{m}$, Ahlstrom, Helsinki, Finland). The fraction collection was triggered automatically by the UV signal at $\lambda=280 \mathrm{~nm}$ (for proanthocyanidin and GT fractions) 
or $350 \mathrm{~nm}$ (for flavonoid fractions). The separation was repeated several times for each fraction, and the eluates containing the respective analytes were combined.

\subsubsection{Flash Chromatography}

The experiments were carried out using a VersaFlash HTFP system equipped with a high flow VersaFlash Piston Pump and a VersaPak ${ }^{\mathrm{TM}} \mathrm{C} 18$ Cartridge $(150 \mathrm{~mm} \times 40 \mathrm{~mm})$ (Supelco, Merck, Darmstadt, Germany). The mobile phase consisted of solvent A (methanol) and solvent $\mathrm{B}$ (water-formic acid, 100:0.1, $v / v$ ). The elution profile was as follows: 0-60 min, $20-40 \%$ A $(v / v$, stepwise gradient, concentration changed by $2.5 \%$ every $7.5 \mathrm{~min}$.). Before the isolation, the analysed fractions (portions of $500 \mathrm{mg}$ ) were dissolved in $3 \mathrm{~mL}$ of methanol-water $(2: 8, v / v)$ and filtered through a PTFE syringe filter $(25 \mathrm{~mm}, 0.2 \mu \mathrm{m}$, Ahlstrom, Helsinki, Finland). The separation was carried out at room temperature $\left(20-25^{\circ} \mathrm{C}\right)$ and a $20 \mathrm{~mL} / \mathrm{min}$ flow rate. The process was repeated several times, and the eluates presenting similar HPLC-PDA profiles (Section 3.7) were combined.

\subsubsection{Isolation Procedure}

The sample of EAF-AP (10.4 g) was dissolved in a small amount of methanol and separated by GPC on Sephadex LH-20 (100 g; $80 \mathrm{~cm} \times 3 \mathrm{~cm}$; Merck, Darmstadt, Germany) using methanol for elution. Based on the chromatographic profile (HPLC-PDA, Section 3.7), eluates were combined to provide several proanthocyanidin and flavonoid fractions, which were independently subjected to preparative HPLC separation (Section 3.4.1) to obtain the pure compounds ECA $(152 \mathrm{mg})$, PB2 $(27.4 \mathrm{mg})$, and CB1 $(200 \mathrm{mg})$ from the proanthocyanidin fractions and HY (175 mg), MQ (141 mg), and GV (37 mg) from the flavonoid fractions. The isolated proanthocyanidins were lyophilised, and the flavonoids were crystallised from methanol or methanol-water $(7: 3, v / v)$.

The sample of BF-AP ( $4.7 \mathrm{~g}$ ) was chromatographed on Sephadex LH-20 (as described for EAF-AP) to separate the flavonoid fraction, which after crystallisation from methanol afforded compound MQK $(125 \mathrm{mg})$.

The WF-AP (5.7 g) sample was separated using flash chromatography (Section 3.4.2) to isolate the fractions of salicylates and flavonoid diglycosides. The fractions were purified on Sephadex LH-20 ( $30 \mathrm{~g} ; 40 \times 2 \mathrm{~cm}$ ), using methanol for elution, to provide compounds GT (125.2 mg), DGQ (38.2 mg), and DGK (10.1 mg), respectively.

\subsection{Structure Elucidation}

Melting points (uncorrected) were determined on a Boetius apparatus (Carl Zeiss, Jena, Germany). The UV-vis spectra were recorded in methanol at $25^{\circ} \mathrm{C}$ on a UV-1601 spectrophotometer (Rayleigh, Beijing, China). The optical rotation $\left([\alpha]_{\mathrm{D}}^{20}\right)$ was measured in methanol on a PolAAr 3001 polarimeter (Optical Activity, Ramsey, U.K.). The CD spectra were recorded on a Jobin-Yvon CD6 spectrometer (Horiba Scientific, Edison, NJ, USA). The analysis of metal ions was performed on a 410 Flame photometer (Sherwood Scientific, Cambridge, UK).

The ${ }^{1} \mathrm{H}$ NMR, ${ }^{13} \mathrm{C}$ NMR, ${ }^{1} \mathrm{H}-{ }^{1} \mathrm{H}$ COSY, HMQC, and $\mathrm{HMBC}$ spectra were recorded at $25^{\circ} \mathrm{C}$ on a Bruker Daltonik III 600 spectrometer (Bruker BioSpin Co., Billerica, MA, USA) in methanol- $d_{4}$, DMSO- $d_{6}$, or water- $d_{2}\left(600 \mathrm{MHz}\right.$ for ${ }^{1} \mathrm{H}$ and $150.9 \mathrm{MHz}$ for $\left.{ }^{13} \mathrm{C}\right)$, with TMS as the internal standard. The ROESY spectrum was recorded at $-30{ }^{\circ} \mathrm{C}$ in acetone- $d_{6}$. The HR-MS spectra were recorded on an AutoSpec Premier Mass Spectrometer (Waters, Milford, MA, USA) coupled with an HP 7890 gas chromatograph (Agilent, Santa Clara, CA, USA).

The acid hydrolysis of glycosides and identification of the absolute configuration of free monosaccharides after their conversion to $1-[(S)-N$-acetyl- $\alpha$-methylbenzylamino $]-1-$ deoxy-alditol pentaacetate derivatives was performed as described earlier [34].

The process of epimerisation was performed according to Seto et al. [55], with slight modifications. First, the sample of (+)-catechin $(50 \mathrm{mg})$ was dissolved in $5 \mathrm{~mL}$ of a Mcllvaine buffer $(\mathrm{pH}=5.0$, containing $0.2 \mathrm{~mol} / \mathrm{L}$ disodium phosphate and $0.1 \mathrm{~mol} / \mathrm{L}$ citric acid, $1: 1$, 
$v / v$ ) and then autoclaved for $30 \mathrm{~min}$ at $120^{\circ} \mathrm{C}$. After cooling to room temperature, the reaction mixture was evaporated to dryness in vacuo and dissolved in methanol (1 mL). The product formed from (+)-catechin, i.e., (+)-epicatechin $(15 \mathrm{mg})$, was isolated by GPC on Sephadex LH-20 (60 g; $80 \mathrm{~cm} \times 3 \mathrm{~cm})$ with methanol as an eluent and finally purified by crystallisation from methanol. The structure was confirmed by NMR studies and optical rotation analysis [55].

The thiolysis was performed according to Meagher et al. [56]. Briefly, $200 \mu \mathrm{L}$ of the solution of hydrochloric acid in methanol $(3.3: 96.7, v / v)$ and $400 \mu \mathrm{L}$ of the solution of benzyl mercaptan in methanol $(5: 95, v / v)$ was added to the vials containing $200 \mu \mathrm{L}$ of the solutions of CB1 and PB2 in methanol (4 mg/mL each). The mixtures were heated at $40{ }^{\circ} \mathrm{C}$ for $30 \mathrm{~min}$ in a heating block and cooled to room temperature. The obtained thiolysates were immediately analysed by HPLC-PDA versus the standards of (-)-epicatechin and (+)-epicatechin, obtained in the epimerisation process. The analyses were performed at $25{ }^{\circ} \mathrm{C}$ on the Hitachi HPLC system (Section 3.7) using a chiral column Lux Cellulose-2 $(5.0 \mu \mathrm{m}, 150 \mathrm{~mm} \times 4.6 \mathrm{~mm}$; Phenomenex, Torrance, CA, USA). The mobile phase was hexane-isopropanol-50\% $(w / w)$ acetic acid (40:60:1, $v / v / v$, isocratic elution). The flow rate was $0.6 \mathrm{~mL} / \mathrm{min}$, the injection volume was $20 \mu \mathrm{L}$, and detection was set at $280 \mathrm{~nm}$.

Compound MQ; quercetin 3-O- $\beta$-D-glucuronopyranoside (miquelianin). Yellow needles: m.p. $220-223{ }^{\circ} \mathrm{C}$; UV (methanol) $\lambda_{\max } \mathrm{nm}$ : 256, 298, 358; ESI-MS ${ }^{2} \mathrm{~m} / z$ (intensity): $[\mathrm{M}+\mathrm{H}]^{+} 479$ (100), $\mathrm{MS}^{2}:[\mathrm{M}+\mathrm{H}-\text { glucuronic acid }]^{+} 303$ (64.1); [M - H] $]^{-} 477(100), \mathrm{MS}^{2}$ : $[\mathrm{M}-\mathrm{H} \text {-glucuronic acid }]^{-} 301$ (91.5); ${ }^{1} \mathrm{H}$ NMR (methanol- $\left.d_{4}\right) \delta \mathrm{ppm:} 7.75(1 \mathrm{H}, d, J=2.3 \mathrm{~Hz}$, H-2' $) ; 7.64\left(1 \mathrm{H}, d d, J_{1}=2.3 \mathrm{~Hz}, J_{2}=8.3 \mathrm{~Hz}, \mathrm{H}-6^{\prime}\right) ; 6.89\left(1 \mathrm{H}, d, J=8.3 \mathrm{~Hz}, \mathrm{H}-5^{\prime}\right) ; 6.44(1 \mathrm{H}$, $d, J=2.3 \mathrm{~Hz}, \mathrm{H}-8) ; 6.25(1 \mathrm{H}, d, J=2.3 \mathrm{~Hz}, \mathrm{H}-6) ; 5.38\left(1 \mathrm{H}, d, J=7.5 \mathrm{~Hz}, \mathrm{H}-1^{\prime \prime}\right) ; 3.76(1 \mathrm{H}$, $\left.d, J=9.8 \mathrm{~Hz}, \mathrm{H}-5^{\prime \prime}\right) ; 3.63\left(1 \mathrm{H}, d d, J_{1}=9.0 \mathrm{~Hz}, J_{2}=9.8 \mathrm{~Hz}, \mathrm{H}-4^{\prime \prime}\right) ; 3.56\left(1 \mathrm{H}, d d, J_{1}=7.5 \mathrm{~Hz}\right.$, $\left.J_{2}=9.0 \mathrm{~Hz}, \mathrm{H}-2^{\prime \prime}\right) ; 3.52\left(1 \mathrm{H}, d d, J_{1}=9.0 \mathrm{~Hz}, J_{2}=9.0 \mathrm{~Hz}, \mathrm{H}-3^{\prime \prime}\right) ;{ }^{13} \mathrm{C} \mathrm{NMR}\left(\right.$ methanol- $\left.d_{4}\right) \delta$ ppm: 160.1 (C-2); 136.6 (C-3); 180.3 (C-4); 164.0 (C-5); 100.9 (C-6); 167.0 (C-7); 95.8 (C-8); 159.5 (C-9); 106.7 (C-10); $123.9\left(\mathrm{C}-1^{\prime}\right) ; 118.5\left(\mathrm{C}-2^{\prime}\right) ; 146.9\left(\mathrm{C}-3^{\prime}\right) ; 150.9\left(\mathrm{C}-4^{\prime}\right) ; 117.1\left(\mathrm{C}-5^{\prime}\right)$; $124.4\left(\mathrm{C}-6^{\prime}\right) ; 105.4\left(\mathrm{C}-1^{\prime \prime}\right) ; 76.5\left(\mathrm{C}-2^{\prime \prime}\right) ; 78.8\left(\mathrm{C}-3^{\prime \prime}\right) ; 73.9\left(\mathrm{C}-4^{\prime \prime}\right) ; 78.2\left(\mathrm{C}-5^{\prime \prime}\right) ; 174.1\left(\mathrm{C}-6^{\prime \prime}\right) ;{ }^{1} \mathrm{H}$ NMR (DMSO- $\left.d_{6}\right) \delta$ ppm: $7.70\left(1 \mathrm{H}, d, J=2.3 \mathrm{~Hz}, \mathrm{H}-2^{\prime}\right) ; 7.56\left(1 \mathrm{H}, d d, J_{1}=2.3 \mathrm{~Hz}, J_{2}=8.3 \mathrm{~Hz}\right.$, H-6 $\left.{ }^{\prime}\right) ; 6.85\left(1 \mathrm{H}, d, J=8.3 \mathrm{~Hz}, \mathrm{H}-5^{\prime}\right) ; 6.42(1 \mathrm{H}, d, J=2.3 \mathrm{~Hz}, \mathrm{H}-8) ; 6.22(1 \mathrm{H}, d, J=2.3 \mathrm{~Hz}$, $\mathrm{H}-6) ; 5.46\left(1 \mathrm{H}, d, J=7.5 \mathrm{~Hz}, \mathrm{H}-1^{\prime \prime}\right) ; 3.56\left(1 \mathrm{H}, d, J=9.8 \mathrm{~Hz}, \mathrm{H}-5^{\prime \prime}\right) ; 3.37\left(1 \mathrm{H}, d d, J_{1}=8.7 \mathrm{~Hz}\right.$, $\left.J_{2}=9.8 \mathrm{~Hz}, \mathrm{H}-4^{\prime \prime}\right) ; 3.25-3.33\left(2 \mathrm{H}, m, \mathrm{H}-2^{\prime \prime}\right.$ and $\left.\mathrm{H}-3^{\prime \prime}\right)$. For trivial atom numbering see chemical formula of MQ (Figure 3).

Compound MQK; quercetin 3-O- $\beta$-D-glucuronopyranoside potassium salt (miquelianin potassium salt). Pale yellow needles: m.p. $>360{ }^{\circ} \mathrm{C}$; UV $(75 \% v / v$ aqueous methanol) $\lambda_{\max }$ nm: 256, 299, 361; HR-ESI-MS m/z: [M - H] $]^{-} 515.0234\left(\mathrm{C}_{21} \mathrm{H}_{17} \mathrm{O}_{13} \mathrm{~K}\right)$; ESI-MS ${ }^{2} \mathrm{~m} / z$ (intensity): $[\mathrm{M}+\mathrm{H}]^{+} 479$ (100), $\mathrm{MS}^{2}$ : [M + H-glucuronic acid $]^{+} 303$ (64.1); $[\mathrm{M}-\mathrm{H}]^{-} 477$ (100), $\mathrm{MS}^{2}$ : [M - H-glucuronic acid $]^{-} 301$ (91.5); flame photometry ( $\mathrm{K}^{+}$ions); ${ }^{1} \mathrm{H}$ NMR (DMSO- $\left.d_{6}\right) \delta$ ppm: $8.46\left(1 \mathrm{H}, d, J=2.3 \mathrm{~Hz}, \mathrm{H}-2^{\prime}\right) ; 7.29\left(1 \mathrm{H}, d d, J_{1}=2.3 \mathrm{~Hz}, J_{2}=8.3 \mathrm{~Hz}, \mathrm{H}-6^{\prime}\right)$; $6.82\left(1 \mathrm{H}, d, J=8.3 \mathrm{~Hz}, \mathrm{H}-5^{\prime}\right) ; 6.35(1 \mathrm{H}, d, J=2.3 \mathrm{~Hz}, \mathrm{H}-8) ; 6.17(1 \mathrm{H}, d, J=2.3 \mathrm{~Hz}, \mathrm{H}-6) ; 5.23$ $\left(1 \mathrm{H}, d, J=7.5 \mathrm{~Hz}, \mathrm{H}-1^{\prime \prime}\right) ; 3.39\left(1 \mathrm{H}, d, J=9.8 \mathrm{~Hz}, \mathrm{H}-5^{\prime \prime}\right) ; 3.27\left(1 \mathrm{H}, d d, J_{1}=8.7 \mathrm{~Hz}, J_{2}=9.8 \mathrm{~Hz}\right.$, $\left.\mathrm{H}-4^{\prime \prime}\right) ; 3.25\left(1 \mathrm{H}, d d, J_{1}=7.5 \mathrm{~Hz}, J_{2}=8.7 \mathrm{~Hz}, \mathrm{H}-2^{\prime \prime}\right) ; 3.21\left(1 \mathrm{H}, d d, J_{1}=8.7 \mathrm{~Hz}, J_{2}=8.7 \mathrm{~Hz}\right.$, H-3" $) ;{ }^{13}$ C NMR (DMSO-d 6 ) $\delta$ ppm: 157.9 (C-2); 134.2 (C-3); 177.7 (C-4); 161.1 (C-5); 99.2

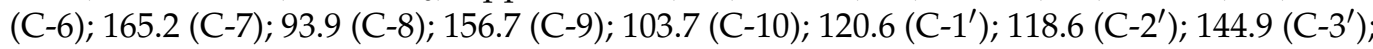
$148.5\left(\mathrm{C}-4^{\prime}\right) ; 115.6\left(\mathrm{C}-5^{\prime}\right) ; 120.4\left(\mathrm{C}-6^{\prime}\right) ; 103.5\left(\mathrm{C}-1^{\prime \prime}\right) ; 74.0\left(\mathrm{C}-2^{\prime \prime}\right) ; 76.9\left(\mathrm{C}-3^{\prime \prime}\right) ; 71.9\left(\mathrm{C}-4^{\prime \prime}\right) ; 74.5$ $\left(\mathrm{C}-5^{\prime \prime}\right) ; 172.2\left(\mathrm{C}-6^{\prime \prime}\right)$. For trivial atom numbering see chemical formula of MQK (Figure 3 ).

Compound DGQ; quercetin 3-O- $\beta$-D-xylopyranosyl- $(1 \rightarrow 2)-\beta$-D-glucuronopyranoside (wintergreenoside A). Yellow amorphous solid: m.p. $217-221^{\circ} \mathrm{C}$; UV (methanol) $\lambda_{\max } \mathrm{nm}$ : 266, 282, 356; HR-ESI-MS $m / z$ : $[\mathrm{M}-\mathrm{H}]^{-} 609.1078\left(\mathrm{C}_{26} \mathrm{H}_{25} \mathrm{O}_{17}\right)$; ESI-MS ${ }^{2} m / z$ (intensity): $[\mathrm{M}+\mathrm{H}]^{+} 611(100), \mathrm{MS}^{2}:[\mathrm{M}+\mathrm{H} \text {-xylose }]^{+} 479$ (53.9), [M + H-xylose-glucuronic acid $]^{+} 303$ (42.1); $[\mathrm{M}-\mathrm{H}]^{-} 609$ (100), $\mathrm{MS}^{2}$ : [M - H-xylose-glucuronic acid $]^{-} 301$ (68.4). ${ }^{1} \mathrm{H}$ and ${ }^{13} \mathrm{C}$ NMR data (methanol- $d_{4}$ and water- $d_{2}$ ): see Table 1.

Compound DGK; kaempferol 3-O- $\beta$-D-xylopyranosyl- $(1 \rightarrow 2)-\beta$-D-glucuronopyranoside (wintergreenoside B). Yellow amorphous solid: m.p. $210-217{ }^{\circ} \mathrm{C}$; UV (methanol) 
$\lambda_{\max }$ nm: 260, 300, 344; HR-ESI-MS $m / z:[\mathrm{M}-\mathrm{H}]^{-} 593.1136\left(\mathrm{C}_{26} \mathrm{H}_{25} \mathrm{O}_{16}\right) ; \mathrm{ESI}^{-\mathrm{MS}^{2}} \mathrm{~m} / z$ (intensity): $[\mathrm{M}+\mathrm{H}]^{+} 595$ (100), $\mathrm{MS}^{2}:[\mathrm{M}+\mathrm{H} \text {-xylose }]^{+} 463$ (72.2), [M + H-xylose-glucuronic acid $]^{+} 287$ (51.9); [M - H] ${ }^{-} 593$ (100), $\mathrm{MS}^{2}$ : [M - H-xylose-glucuronic acid $]^{-} 285$ (82.1). ${ }^{1} \mathrm{H}$ and ${ }^{13} \mathrm{C}$ NMR data (methanol- $\left.d_{4}\right)$ : see Table 1 .

Compound CB1; (-)-epicatechin- $(4 \beta \rightarrow 8,2 \beta \rightarrow O \rightarrow 7)-(-)$-epicatechin- $(4 \beta \rightarrow 8)-(-)$-epicatechin (cinnamtannin B-1). Pale pink amorphous solid: m.p. $202-204{ }^{\circ} \mathrm{C} ;[\alpha]_{\mathrm{D}}^{20}=+93.0^{\circ}$ ( $c=1.00 \mathrm{~g} / 100 \mathrm{~mL}$, methanol); UV (methanol) $\lambda_{\max } \mathrm{nm}: 278 ; \mathrm{CD}(c=1.57 \mathrm{mmol} / \mathrm{L}$, methanol) $[\Theta]_{199}+140275,[\Theta]_{207}-380803,[\Theta]_{228}+23491,[\Theta]_{239}+165245 \mathrm{sh},[\Theta]_{270}-25296$; ESI-MS $2 \mathrm{~m} / \mathrm{z}$ (intensity): $[\mathrm{M}+\mathrm{H}]^{+} 865$ (100), $\mathrm{MS}^{2}$ : [M + H - 152] 713 (57.6); [M - H] 863 (100), $\mathrm{MS}^{2}:[\mathrm{M}-\mathrm{H}-152]^{-} 711$ (63.5). ${ }^{1} \mathrm{H}$ and ${ }^{13} \mathrm{C}$ NMR data (methanol- $\left.d_{4}\right)$ : see Table S3.

\subsection{Biological Activity Tests}

\subsubsection{Non-Cellular In Vitro Models}

The FRAP was determined according to Olszewska and Michel [57] and expressed in mol of ferrous ions $\left(\mathrm{Fe}^{2+}\right)$ produced by $1 \mathrm{~mol}$ of an analyte, calculated from the calibration curve of ferrous sulphate. The $\mathrm{O}_{2}{ }^{\bullet-}$ scavenging capacity was evaluated according to Michel et al. [13] and expressed as $\mathrm{SC}_{50}$ values, calculated from the concentrationscavenging curve. The ability of the analytes to inhibit COX-2 and HYAL was evaluated by ELISA test following the manufacturer's instructions (Cayman Chemical, Ann Arbor, MI, USA) and according to Matczak et al. [58], respectively, and expressed as $\mathrm{IC}_{50}$ values, calculated from the concentration-inhibition curves. The analytes were tested at the final concentrations of $1.5-65 \mu \mathrm{M}, 1.5-1500.0 \mu \mathrm{M}, 0.15-3.70 \mathrm{mM}$, and 5.0-200 $\mu \mathrm{M}$ for the FRAP, $\mathrm{O}_{2}^{\bullet-}, \mathrm{COX}-2$, and HYAL inhibition assays, respectively. The standards of ascorbic acid and Trolox (FRAP, $\mathrm{O}_{2}^{\bullet-}$ scavenging) or dexamethasone and indomethacin were used as positive controls in antioxidant and anti-inflammatory activity tests, respectively. A SPECTROstar Nano (BMG Labtech GmbH, Ortenberg, Germany) microplate reader and 96-well plates were used for the measurements.

\subsubsection{Cellular Model of Human Neutrophils Ex Vivo}

Neutrophils were isolated from buffy coat fractions of human blood purchased from the Warsaw Blood Donation Centre. The blood samples were collected from healthy adult human donors (18-35 years old), and routine laboratory tests showed all values within the normal ranges. The study conformed to the principles of the Declaration of Helsinki (the approval of the bioethics committee is not required).

The isolation was performed using the dextran sedimentation method before hypotonic lysis of erythrocytes and centrifugation in a Ficoll Hypaque gradient as previously described [11]. The purity of the cells exceeded 97\%.

The potential cytotoxicity (influence on cell wall integrity) of the analytes was evaluated by flow cytometry using propidium iodide (PI) staining according to Michel et al. [11]. The analytes were tested at the levels of $25-75 \mu \mathrm{M}$. The results were expressed as a percentage of $\mathrm{PI}(+)$ cells (displaying high permeability to PI).

The influence of the analytes on the pro-oxidant and pro-inflammatory functions of neutrophils was evaluated as described previously $[11,18]$. Briefly, the ROS level in $f$ MLPstimulated neutrophils was determined by the luminol-dependent chemiluminescence method; the ELISA tests measured the release of IL- $1 \beta$ and TNF- $\alpha$ from LPS-stimulated neutrophils following the manufacturer's instruction (BD Biosciences, San Jose, CA, USA), and the secretion of ELA-2 from neutrophils stimulated by $f$ MLP and cytochalasin B was determined using SAAVNA as a substrate. The standards of QU (ROS, ELA-2) or dexamethasone (IL-1 $\beta, \mathrm{TNF}-\alpha$ ) were used as positive controls, respectively. The analytes were tested at the levels of 25-75 $\mu \mathrm{M}$. The assays were performed using 96-well plates and a microplate reader (Synergy 4, BioTek, Winooski, VT, USA). 


\subsection{Quantitative HPLC-PDA Assay}

The analyses were performed on an HPLC VWR-Hitachi LaChrom Elite ${ }^{\circledR}$ System equipped with a PDA Detector (scanning in the wavelength range of 220-450 nm), thermostated autosampler, and column compartments, and a quaternary gradient pump (VWR, Hitachi, Tokyo, Japan). Separations were carried out on a C18 Ascentis ${ }^{\circledR}$ Express column $(2.7 \mu \mathrm{m}, 75 \mathrm{~mm} \times 4.6 \mathrm{~mm}$ i.d.; Supelco, Merck, Darmstadt, Germany), guarded by a C18 Ascentis ${ }^{\circledR} \mathrm{C} 18$ Supelguard guard column $(3 \mu \mathrm{m}, 20 \mathrm{~mm} \times 4 \mathrm{~mm}$ i.d.; Supelco). The elution system consisted of solvent A (water-85\% orthophosphoric acid, 100:0.5, v/w, $\mathrm{pH} 2.0$ ) and solvent $\mathrm{B}$ (acetonitrile). The optimised elution profile is shown in Table 3. The flow rate was $1.4 \mathrm{~mL} / \mathrm{min}$, the injection volume was $5 \mu \mathrm{L}$, and the column was maintained at $18{ }^{\circ} \mathrm{C}$. The detection wavelength was set at $280,285,325,350$, or $370 \mathrm{~nm}$, depending on the analyte (Table 4). Before injection, samples of the extracts $(1-50 \mathrm{mg})$ were dissolved in $10 \mathrm{~mL}$ of methanol-water $(75: 25, v / v)$ and filtered through a PTFE syringe filter $(25 \mathrm{~mm}, 0.2 \mu \mathrm{m}$, Ahlstrom, Helsinki, Finland). Results were calculated in $\mathrm{mg} / \mathrm{g} \mathrm{dw}$ of the extracts.

\subsection{Validation of the HPLC-PDA Method}

The analytical method was validated by determining the selectivity, linearity, precision, accuracy, and stability of each analyte [52].

The method's selectivity and peak purity were evaluated by comparison of the retention times and UV-vis spectra with reference standards using an automated match system.

Linearity was tested using the standard stock solution containing eleven reference compounds, dissolved and serially diluted (in triplicate) with methanol-water $(75: 25, v / v)$ to six concentration levels $(2 \%, 10 \%, 25 \%, 50 \%, 75 \%$, and $100 \%$ of the stock concentration). Each replicate solution was injected into the HPLC system in triplicate. Two linear regression models were tested $(\mathrm{y}=a \mathrm{x}+b ; \mathrm{y}=a \mathrm{x})$, and the $F$ - and $t$-tests were applied to check the statistical significance of the regression equations, slopes, and intercepts at a $99 \%$ confidence level.

The LOD and LOQ values were determined using a serial dilution of the standard solution. The lowest concentrations with the signal-to-noise ratio $(\mathrm{S} / \mathrm{N})$ of 3 were accepted as LODs, while the levels with S/N above 10 were accepted as LOQs if the RSD values for peak area were not higher than $15 \%$.

The repeatability (intra-day variability) and the intermediate precision (inter-day variability) were tested for retention times and peak areas using the standard solution at $10 \%$, and $100 \%$ of the stock concentration and the aerial parts extract of G. procumbens (ME-AP). The repeatability was determined by triplicate analysis of each sample within $24 \mathrm{~h}$, while the intermediate precision was evaluated on three non-consecutive days within two weeks.

The accuracy was tested in the real sample ME-AP by the standard addition/recovery procedure at three different levels of each standard, within the analytical range investigated. The samples were prepared in triplicate by spiking the extract with the standard solution. The replicate samples were analysed in triplicate. The accuracy was calculated as the mean recovery of the analytes from the spiked versus the non-spiked extracts.

\subsection{Statistical Analysis}

The results were expressed as means \pm standard deviation (SD) for replicate determinations. The statistical analyses (calculation of SD, one-way analysis of variance, HSD Tukey tests, and linearity studies) were performed using the Statistica12Pl software for Windows (StatSoft Inc., Krakow, Poland), with $p$ values less than 0.05 being regarded as significant.

\section{Conclusions}

This work is the first integrated phytochemical and biological activity study of individual polyphenols of G. procumbens aerial parts, leaf, and stem extracts. The LC-MS/MS analysis, isolation, and spectroscopic experiments led to the selection and complete structural 
identification of eleven model compounds representing all classes of Gaultheria polyphenols, including one new natural product. In addition, the second new natural compound was identified among minor components of the plant. The biological activity tests revealed that the model constituents significantly down-regulated the pro-oxidant and pro-inflammatory functions of human neutrophils, inhibited two key pro-inflammatory enzymes, and most of them, except GT, exerted potent direct antioxidant capacity. As these mechanisms have been previously connected to the health benefits of Gaultheria plants [10-13,18-21], all eleven compounds might be considered active markers for the standardisation of the respective extracts. Therefore, the proposed HPLC-PDA method, fully validated during the study using these markers as calibration standards, might be recommended as a simple, accurate and reproducible tool for that purpose.

Supplementary Materials: The following are available online at https:/ / www.mdpi.com/article/10 .3390/ijms222111532/s1.

Author Contributions: M.A.O. and P.M. conceived and designed the experiments; P.M., A.M. and S.G. performed isolation experiments; P.M., M.A.O. and A.O. performed structural studies; P.M. and S.G. performed anti-inflammatory and antioxidant activity studies; M.A.O. and P.M. wrote the paper. All authors read and approved the final manuscript.

Funding: This work was financially supported by the National Science Centre, Poland (Grant Project: UMO-2015/19/N/NZ7/00959).

Institutional Review Board Statement: Not applicable.

Informed Consent Statement: Not applicable.

Data Availability Statement: Not applicable.

Acknowledgments: This project was carried out using CePT infrastructure financed by the European Regional Development Fund within the Operational Programme "Innovative economy" for 2007-2013.

Conflicts of Interest: The authors declare no conflict of interest.

\section{Abbreviations}

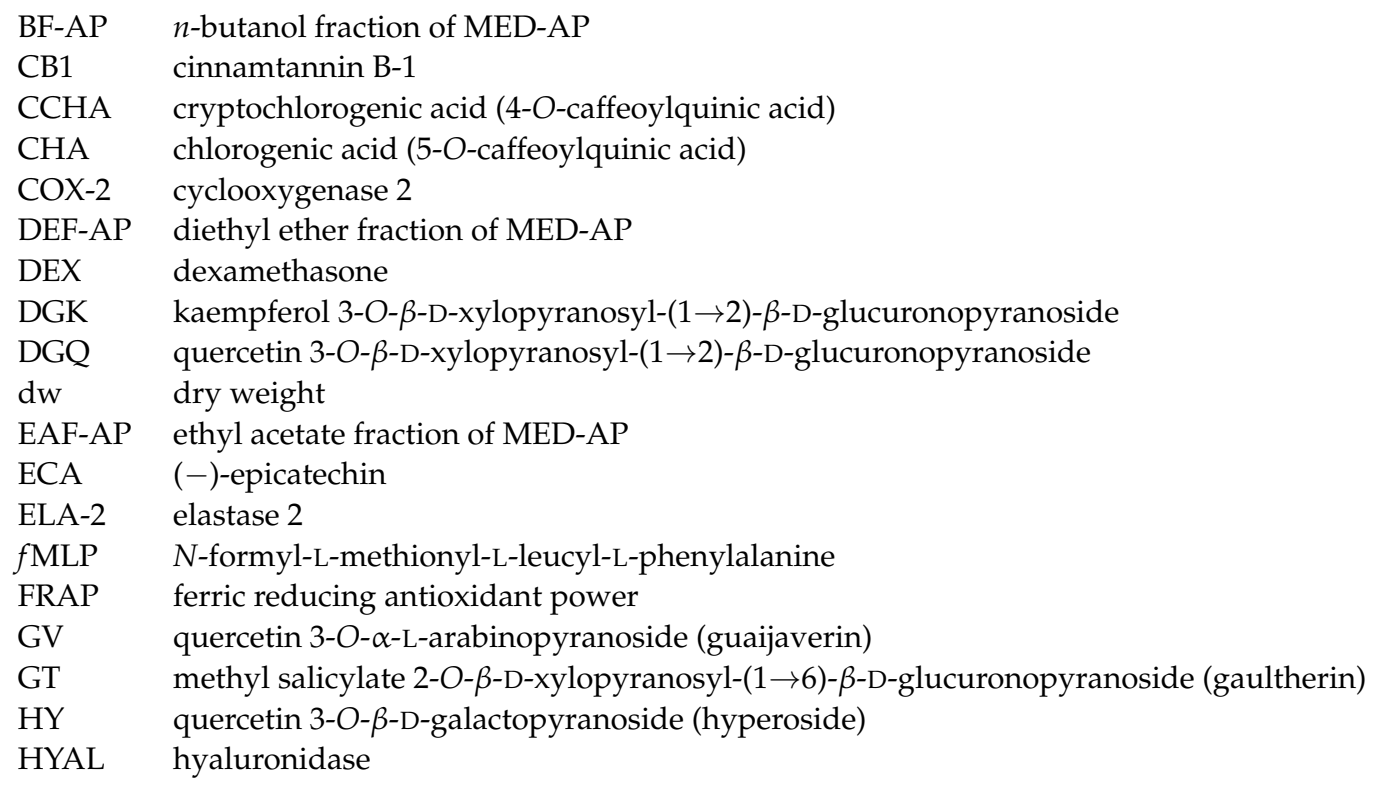




$\begin{array}{ll}\text { IL } & \text { interleukin } \\ \text { IND } & \text { indomethacin } \\ \text { IQ } & \text { quercetin 3-O- } \beta \text {-D-glucopyranoside (isoquercitrin) } \\ \text { KG } & \text { kaempferol 3-O- } \beta \text {-D-glucuronopyranoside } \\ \text { LPS } & \text { bacterial lipopolysaccharide } \\ \text { ME-AP } & \text { methanol-water }(75: 25, v / v) \text { extract of aerial parts } \\ \text { MED-AP } & \text { defatted methanol-water }(75: 25, v / v) \text { extract of aerial parts } \\ \text { ME-L } & \text { methanol-water }(75: 25, v / v) \text { extract of leaves } \\ \text { ME-S } & \text { methanol-water }(75: 25, v / v) \text { extract of stems } \\ \text { MQ } & \text { quercetin 3-O- } \beta \text {-D-glucuronopyranoside }(\text { miquelianin) } \\ \text { MQK } & \text { quercetin 3-O- } \beta \text {-D-glucuronopyranoside potassium salt } \\ \text { NCHA } & \text { neochlorogenic acid }(3-O-\text {-caffeoylquinic acid) } \\ \mathrm{O}_{2} \bullet- & \text { superoxide anion } \\ \text { PB2 } & \text { procyanidin B2 } \\ \text { QU } & \text { quercetin } \\ \text { ROS } & \text { reactive oxygen species } \\ \text { TNF- } \alpha & \text { tumour necrosis factor } \alpha \\ \text { WF-AP } & \text { water fraction of MED-AP }\end{array}$

\section{References}

1. Sendker, J.; Sheridan, H. Composition and quality control of herbal medicines. In Toxicology of Herbal Products, 1st ed.; Pelkonen, O., Duez, P., Vuorela, P.M., Vuorela, H., Eds.; Springer: Berlin/Heidelberg, Germany; New York, NY, USA, 2017; pp. 29-65. [CrossRef]

2. Tistaert, C.; Dejaegher, B.; Heyden, Y. Vander chromatographic separation techniques and data handling methods for herbal fingerprints: A review. Anal. Chim. Acta 2011, 690, 148-161. [CrossRef] [PubMed]

3. Han, Y.; Zhou, M.; Wang, L.; Ying, X.; Peng, J.; Jiang, M.; Bai, G.; Luo, G. Comparative evaluation of different cultivars of Flos Chrysanthemi by an anti-inflammatory-based NF- $\mathrm{kB}$ reporter gene assay coupled to UPLC-Q/TOF MS with PCA and ANN. J. Ethnopharmacol. 2015, 174, 387-395. [CrossRef] [PubMed]

4. EMA. Guideline on Specifications: Test Procedures and Acceptance Criteria for Herbal Substances, Herbal Preparations and Herbal Medicinal Products/Traditional Herbal Medicinal Products; EMA/HMPC/162241/2005 Rev. 3; EMA: Amsterdam, The Netherlands, 2018; Volume 44, pp. 1-32.

5. Kharyuk, P.; Nazarenko, D.; Oseledets, I.; Rodin, I.; Shpigun, O.; Tsitsilin, A.; Lavrentyev, M. Employing fingerprinting of medicinal plants by means of LC-MS and machine learning for species identification task. Sci. Rep. 2018, 8, 17053. [CrossRef] [PubMed]

6. Wolfender, J.L.; Nuzillard, J.M.; Van Der Hooft, J.J.J.; Renault, J.H.; Bertrand, S. Accelerating metabolite identification in natural product research: Toward an ideal combination of liquid chromatography-high-resolution tandem mass spectrometry and NMR profiling, in silico databases, and chemometrics. Anal. Chem. 2019, 91, 704-742. [CrossRef]

7. Liu, W.R.; Qiao, W.L.; Liu, Z.Z.; Wang, X.H.; Jiang, R.; Li, S.Y.; Shi, R.B.; She, G.M. Gaultheria: Phytochemical and pharmacological characteristics. Molecules 2013, 18, 12071-12108. [CrossRef]

8. Luo, B.; Gu, R.; Kennelly, E.J.; Long, C. Gaultheria ethnobotany and bioactivity: Blueberry relatives with anti-inflammatory, antioxidant, and anticancer constituents. Curr. Med. Chem. 2017, 25, 5168-5176. [CrossRef]

9. Ribnicky, D.M.; Poulev, A.; Raskin, I. The determination of salicylates in Gaultheria procumbens for use as a natural aspirin alternative. J. Nutraceuticals Funct. Med. Foods 2003, 4, 39-52. [CrossRef]

10. Zhang, D.; Liu, R.; Sun, L.; Huang, C.; Wang, C.; Zhang, D.M.; Zhang, T.T.; Du, G.H. Anti-inflammatory activity of methyl salicylate glycosides isolated from Gaultheria yunnanensis (Franch.) Rehder. Molecules 2011, 16, 3875-3884. [CrossRef]

11. Michel, P.; Granica, S.; Magiera, A.; Rosińska, K.; Jurek, M.; Poraj, Ł.; Olszewska, M.A. Salicylate and procyanidin-rich stem extracts of Gaultheria procumbens L. inhibit pro-inflammatory enzymes and suppress pro-inflammatory and pro-oxidant functions of human neutrophils ex vivo. Int. J. Mol. Sci. 2019, 20, 1753. [CrossRef]

12. Zhang, B.; Li, J.-B.; Zhang, D.-M.; Ding, Y.; Du, G.-H. Analgesic and anti-inflammatory activities of a fraction rich in gaultherin isolated from Gaultheria yunnanensis (Franch.) Rehder. Biol Pharm Bull 2007, 30, 465-469. [CrossRef] [PubMed]

13. Michel, P.; Dobrowolska, A.; Kicel, A.; Owczarek, A.; Bazylko, A.; Granica, S.; Piwowarski, J.P.; Olszewska, M.A. Polyphenolic profile, antioxidant and anti-inflammatory activity of Eastern teaberry (Gaultheria procumbens L.) leaf extracts. Molecules 2014, 19, 20498-20520. [CrossRef] [PubMed]

14. Liang, N.; Kitts, D.D. Role of chlorogenic acids in controlling oxidative and inflammatory stress conditions. Nutrients $2016,8,16$. [CrossRef] [PubMed]

15. Rathee, P.; Rathee, S.; Chaudhary, H.; Kohli, K.; Rathee, D.; Kumar, V. Mechanism of action of flavonoids as anti-inflammatory agents: A review. Inflamm. Allergy Drug Targets 2012, 8, 229-235. [CrossRef] [PubMed]

16. Yang, L.; Xian, D.; Xiong, X.; Lai, R.; Song, J.; Zhong, J. Proanthocyanidins against oxidative stress: From molecular mechanisms to clinical applications. BioMed Res. Int. 2018, 2018, 8584136. [CrossRef] 
17. Saleem, A.; Harris, C.S.; Asim, M.; Cuerrier, A.; Martineau, L.; Haddad, P.S.; Arnason, J.T. A RP-HPLC-DAD-APCI/MSD method for the characterisation of medicinal Ericaceae used by the Eeyou Istchee Cree First Nations. Phytochem. Anal. 2010, 21, 328-339. [CrossRef]

18. Michel, P.; Granica, S.; Rosinska, K.; Rojek, J.; Poraj, L.; Olszewska, M.A. Biological and chemical insight into Gaultheria procumbens fruits: A rich source of anti-inflammatory and antioxidant salicylate glycosides and procyanidins for food and functional application. Food Funct. 2020, 11, 7532-7544. [CrossRef]

19. Zhang, X.; Sun, J.; Xin, W.; Li, Y.; Ni, L.; Ma, X.; Zhang, D.; Zhang, D.; Zhang, T.; Du, G. Anti-inflammation effect of methyl salicylate 2-O- $\beta$-D-lactoside on adjuvant induced-arthritis rats and lipopolysaccharide (LPS)-treated murine macrophages RAW264.7 cells. Int. Immunopharmacol. 2015, 25, 88-95. [CrossRef]

20. Xin, W.; Huang, C.; Zhang, X.; Zhang, G.; Ma, X.; Sun, L.; Wang, C.; Zhang, D.; Zhang, T.; Du, G. Evaluation of the new anti-inflammatory compound ethyl salicylate $2-\mathrm{O}-\beta-\mathrm{D}-$ glucoside and its possible mechanism of action. Int. Immunopharmacol. 2013, 15, 303-308. [CrossRef]

21. Zhang, T.; Sun, L.; Liu, R.; Zhang, D.; Lan, X.; Huang, C.; Xin, W.; Wang, C.; Zhang, D.; Du, G. A novel naturally occurring salicylic acid analogue acts as an anti-inflammatory agent by inhibiting nuclear factor-kappaB activity in RAW264.7 macrophages. Mol. Pharm. 2012, 9, 671-677. [CrossRef]

22. Clifford, M.N.; Johnston, K.L.; Knight, S.; Kuhnert, N. Hierarchical scheme for LC-MSn identification of chlorogenic acids. J. Agric. Food Chem. 2003, 51, 2900-2911. [CrossRef]

23. Hamed, A.I.; Al-Ayed, A.S.; Moldoch, J.; Piacente, S.; Oleszek, W.; Stochmal, A. Profiles analysis of proanthocyanidins in the argun nut (Medemia argun-An Ancient Egyptian palm) by LC-ESI-MS/MS. J. Mass Spectrom. 2014, 49, 306-315. [CrossRef]

24. Vukics, V.; Guttman, A. Structural characterisation of flavonoid glycosides by multi-stage mass spectrometry. Mass Spectrom. Rev. 2010, 29, 1-12. [CrossRef]

25. Li, H.J.; Deinzer, M.L. The mass spectral analysis of isolated hops A-type proanthocyanidins by electrospray ionization tandem mass spectrometry. J. Mass Spectrom. 2008, 43, 1353-1363. [CrossRef]

26. Baldé, A.M.; Pieters, L.A.; Wray, V.; Kolodziej, H.; Berghe, D.A.V.; Claeys, M.; Vlietinck, A.J. Dimeric and trimeric proanthocyanidins possessing a doubly linked structure from Pavetta owariensis. Phytochemistry 1991, 30, 4129-4135. [CrossRef]

27. Kamiya, K.; Watanabe, C.; Endang, H.; Umar, M.; Satake, T. Studies on the constituents of bark of Parameria laevigata Moldenke. Chem. Pharm. Bull. 2002, 49, 551-557. [CrossRef]

28. Barret, M.W.; Klyne, W.; Scopes, M.P.; Fletcher, A.C.; Porter, L.J.; Haslam, E. Plant proanthocyanidins. Part 6. Ciroptical studies. Part 95. Circulair dichroism of procyanidins. J. Chem. Soc. Perkin Trans. 1979, 1, 2375-2377. [CrossRef]

29. Hatano, T.; Miyatake, H.; Natsume, M.; Osakabe, N.; Takizawa, T.; Ito, H.; Yoshida, T. Proanthocyanidin glycosides and related polyphenols from cacao liquor and their antioxidant effects. Phytochemistry 2002, 59, 749-758. [CrossRef]

30. Esatbeyoglu, T.; Jaschok-Kentner, B.; Wray, V.; Winterhalter, P. Structure elucidation of procyanidin oligomers by low-temperature ${ }^{1} \mathrm{H}$ NMR spectroscopy. J. Agric. Food Chem. 2011, 59, 62-69. [CrossRef]

31. Salas, E.; Le Guernevé, C.; Fulcrand, H.; Poncet-Legrand, C.; Cheynier, V. Structure determination and colour properties of a new directly linked flavanol-anthocyanin dimer. Tetrahedron Lett. 2004, 45, 8725-8729. [CrossRef]

32. López, J.J.; Jardín, I.; Salido, G.M.; Rosado, J.A. Cinnamtannin B-1 as an antioxidant and platelet aggregation inhibitor. Life Sci. 2008, 82, 977-982. [CrossRef]

33. Olszewska, M. Separation of quercetin, sexangularetin, kaempferol and isorhamnetin for simultaneous HPLC determination of flavonoid aglycones in inflorescences, leaves and fruits of three Sorbus species. J. Pharm. Biomed. Anal. 2008, 48, 629-635. [CrossRef] [PubMed]

34. Olszewska, M.A.; Roj, J.M. Phenolic constituents of the inflorescences of Sorbus torminalis (L.) Crantz. Phytochem. Lett. 2011, 4, 151-157. [CrossRef]

35. Markham, K.R.; Geiger, H. ${ }^{1} \mathrm{H}$ nuclear magnetic resonance spectroscopy of flavonoids and their glycosides in hexadeuterodimethylsulfoxide. In The Flavonoids: Advances in Research since 1986; Routledge: Boca Raton, FL, USA, 1994; pp. 441-498.

36. Agrawal, P.K. NMR spectroscopy in the structural elucidation of oligosaccharides and glycosides. Phytochemistry 1992, 31, 3307-3330. [CrossRef]

37. Olszewska, M.; Wolbiś, M. Further flavonoids from the flowers of Prunus spinosa L. Acta Pol. Pharm. Drug Res. 2002, 59, $133-137$.

38. Kajjout, M.; Rolando, C. Regiospecific synthesis of quercetin $O$ - $\beta$-D-glucosylated and $O$ - $\beta$-D-glucuronidated isomers. Tetrahedron 2011, 67, 4731-4741. [CrossRef]

39. Zhang, J.; Huang, N.; Lu, J.C.; Li, X.; Wang, Y.H.; Yang, L.M.; Zheng, Y.T.; Xiao, K. Water-soluble phenolic compounds and their anti-HIV-1 activities from the leaves of Cyclocarya paliurus. J. Food Drug Anal. 2010, 18, 398-404. [CrossRef]

40. Olszewska, M. Flavonoids from Prunus serotina Ehrh. Acta Pol. Pharm. Drug Res. 2005, 62, 127-133.

41. Tarascou, I.; Barathieu, K.; Simon, C.; Ducasse, M.A.; André, Y.; Fouquet, E.; Dufourc, E.J.; de Freitas, V.; Laguerre, M.; Pianet, I. A 3D structural and conformational study of procyanidin dimers in water and hydro-alcoholic media as viewed by NMR and molecular modeling. Magn. Reson. Chem. 2006, 44, 868-880. [CrossRef]

42. Wang, C.; Zhang, T.T.; Du, G.H.; Zhang, D.M. Synthesis and anti-nociceptive and anti-inflammatory effects of Gaultherin and its analogs. J. Asian Nat. Prod. Res. 2011, 13, 817-825. [CrossRef] 
43. Parcheta, M.; Świsłocka, R.; Orzechowska, S.; Akimowicz, M.; Choińska, R.; Lewandowski, W. Recent developments in effective antioxidants: The structure and antioxidant properties. Materials 2021, 14, 1984. [CrossRef]

44. Zhang, B.; He, X.L.; Ding, Y.; Du, G.H. Gaultherin, a natural salicylate derivative from Gaultheria yunnanensis: Towards a better non-steroidal anti-inflammatory drug. Eur. J. Pharmacol. 2006, 530, 166-171. [CrossRef]

45. Ferrer, M.D.; Busquets-Cortés, C.; Capó, X.; Tejada, S.; Tur, J.A.; Pons, A.; Sureda, A. Cyclooxygenase-2 inhibitors as a therapeutic target in inflammatory diseases. Curr. Med. Chem. 2019, 26, 3225-3241. [CrossRef]

46. Girish, K.S.; Kemparaju, K.; Nagaraju, S.; Vishwanath, B.S. Hyaluronidase inhibitors: A biological and therapeutic perspective. Curr. Med. Chem. 2009, 16, 2261-2288. [CrossRef]

47. Wright, H.L.; Moots, R.J.; Bucknall, R.C.; Edwards, S.W. Neutrophil function in inflammation and inflammatory diseases. Rheumatology 2010, 49, 1618-1631. [CrossRef]

48. Hoffman, H.M.; Wanderer, A.A. Inflammasome and IL-1ß-mediated disorders. Curr. Allergy Asthma Rep. 2010, 10. [CrossRef]

49. Kalliolias, G.D.; Ivashkiv, L.B. TNF biology, pathogenic mechanisms and emerging therapeutic strategies. Nat. Rev. Rheumatol. 2016, 12, 49-62. [CrossRef]

50. Henriksen, P.A. The potential of neutrophil elastase inhibitors as anti-inflammatory therapies. Curr. Opin. Hematol. $2014,21$. [CrossRef]

51. Olszewska, M.A. New validated high-performance liquid chromatographic method for simultaneous analysis of ten flavonoid aglycones in plant extracts using a C18 fused-core column and acetonitrile-tetrahydrofuran gradient. J. Sep. Sci. 2012, 35, 2174-2183. [CrossRef]

52. ICH Expert Working Group. Q2 (R1) Validation of Analytical Procedures: Text and Methodology; The European Medicines Agency: Amsterdam, The Netherlands, 1995.

53. AOAC International. Appendix K: Guidelines for Dietary Supplements and Botanicals. AOAC Off. Methods Anal. 2013, 1-32 Available online: https://members.aoac.org/AOAC_Docs/StandardsDevelopment/eoma_appendix_k.pdf (accessed on 22 August 2021).

54. AOAC International. Appendix F: Guidelines for Standard Methods Performance Requirements. AOAC Off. Methods Anal. 2016, 1-18. Available online: http:/ / www.eoma.aoac.org/app_f.pdf (accessed on 22 August 2021).

55. Seto, R.; Nakamura, H.; Nanjo, F.; Hara, Y. Preparation of epimers of tea catechins by heat treatment. Biosci. Biotechnol. Biochem. 1997, 61, 1434-1439. [CrossRef]

56. Meagher, L.P.; Lane, G.; Sivakumaran, S.; Tavendale, M.H.; Fraser, K. Characterization of condensed tannins from Lotus species by thiolytic degradation and electrospray mass spectrometry. Anim. Feed Sci. Technol. 2004, 117, 151-163. [CrossRef]

57. Olszewska, M.A.; Michel, P. Activity-guided isolation and identification of free radical-scavenging components from various leaf extracts of Sorbus aria (L.) Crantz. Nat. Prod. Res. 2012, 26, 243-254. [CrossRef]

58. Matczak, M.; Marchelak, A.; Michel, P.; Owczarek, A.; Piszczan, A.; Kolodziejczyk-Czepas, J.; Nowak, P.; Olszewska, M.A. Sorbus domestica L. leaf extracts as functional products: Phytochemical profiling, cellular safety, pro-inflammatory enzymes inhibition and protective effects against oxidative stress in vitro. J. Funct. Foods 2018, 40, 207-218. [CrossRef] 